The Canadian Mineralogist

Vol. 41, pp. 1203-1224 (2003)

\title{
CRYSTAL CHEMISTRY OF THE ROSENBUSCHITE GROUP
}

\author{
Claes C. CHRISTIANSEN ${ }^{\S}$ and Ole JOHNSEN \\ Geological Museum, University of Copenhagen, Øster Voldgade 5-7, DK-1350 Copenhagen K, Denmark \\ EMIL MAKOVICKY \\ Geological Institute, University of Copenhagen, Øster Voldgade 10, DK-1350 Copenhagen K, Denmark
}

\begin{abstract}
The minerals of the rosenbuschite group are sorosilicates composed of a framework of 6- to 8-corner polyhedra and rows of $\mathrm{Si}_{2} \mathrm{O}_{7}$ dimers. The polyhedra combine into layers ( $O$ layers) and into ribbons by edge sharing. Heterogeneous layers $(H$ layers $)$, composed of the octahedra from the ribbons and the sorosilicate groups, alternate with the $O$ layer into a layered $\mathrm{HOH}$ structure. The 6- to 8-corner polyhedra host a variety of cations: $\mathrm{Na}, \mathrm{Mg}, \mathrm{Ca}, \mathrm{Ti}, \mathrm{Mn}, \mathrm{Fe}, \mathrm{Y}, \mathrm{Zr}, \mathrm{Nb}$ and the REE. Substitutions among these elements affect the geometrical properties of the various polyhedra. Crystal-structure refinements (X-ray diffraction) have been done on five specimens of the rosenbuschite group: götzenite, hainite, kochite (a new member of the group), rosenbuschite and seidozerite. Detailed models for their site occupancies are derived by fitting scattering values of the sites to the chemical composition, and the weighted bond-valence sums to valence sums in an integrated calculation procedure. Results of chemical analyses suggest a series of intermediate compositions between götzenite and kochite. This series may be described as a solid-solution series in which $\mathrm{Zr}$ substitutes for $\mathrm{Ca}$ in one structural position, götzenite being the Ca-rich end-member. Through substitution of $\mathrm{Ti}$ by $\mathrm{Zr}$, still another solid-solution exists between kochite and rosenbuschite, with rosenbuschite as the $\mathrm{Zr}$-rich member. The $\mathrm{Ca}$ $\rightarrow \mathrm{Zr}$ substitution has significant effect on the size of the respective octahedron, as well as on the dimension and distortion of the adjacent polyhedra. The reduction in size of the $\mathrm{Ca} \rightarrow \mathrm{Zr}$ octahedron is partly compensated by an enlargement of the dimensions of the adjacent $\mathrm{Ti}$ octahedron. This change favors the $\mathrm{Ti} \rightarrow \mathrm{Zr}$ substitution at the latter site. Different degrees of distortion in the sorosilicate group and the adjacent $\mathrm{Ca}$, Na octahedra are also associated with the $\mathrm{Ca} \rightarrow \mathrm{Zr}$ substitution. In the $\mathrm{Zr}$-rich seidozerite, a stacking of the $\mathrm{HOH}$ structural layers different from the above-mentioned structures is observed. The change in stacking sequence is closely related to complex geometrical interrelationships between dimensions and distortions of the $\mathrm{Zr}$ - and $\mathrm{Mn}-$ dominated octahedra. Chemical data indicate that seidozerite does not form a solid solution with rosenbuschite.
\end{abstract}

Keywords: rosenbuschite group, seidozerite, crystal chemistry, single-crystal X-ray diffraction, electron-microprobe data, cation order, polyhedron geometry.

\section{SOMMAIRE}

Les minéraux du groupe de la rosenbuschite sont des sorosilicates dont la trame est composée de polyèdres à de six à huit coins et des rangées de dimères $\mathrm{Si}_{2} \mathrm{O}_{7}$. Les polyèdres sont agencés en couches (niveaux $O$ ) et en rubans par partage d'arêtes. Les couches hétérogènes (niveaux $H$ ), composée d'octaèdres des rubans et de groupes sorosilicatés, alternent avec les niveaux $O$ pour former une structure stratifiée $\mathrm{HOH}$. Les polyèdres à de six à huit coins renferment une variété de cations: $\mathrm{Na}, \mathrm{Mg}, \mathrm{Ca}, \mathrm{Ti}, \mathrm{Mn}$, $\mathrm{Fe}, \mathrm{Y}, \mathrm{Zr}, \mathrm{Nb}$ et les terres rares. Les substitutions impliquant ces éléments affectent les propriétés géométriques des divers polyèdres. Nous avons effectué par diffraction $\mathrm{X}$ un affinement de la structure de cinq échantillons du groupe de la rosenbuschite: götzenite, hainite, kochite (un nouveau membre du groupe), rosenbuschite et seidozerite. Nous avons dérivé des modèles détaillés de la répartition des cations sur les sites en ajustant les valeurs de la dispersion des rayons $\mathrm{X}$ à ces sites avec la composition chimique, et les sommes pondérées des valences de liaison prédites aux valeurs observées, dans le contexte d'une procédure de calcul intégrée. Les compositions déterminées par analyse semblent indiquer une série de membres intermédiaires entre götzenite et kochite. On peur décrire cette série en termes d'une solution solide dans laquelle le Zr remplace le Ca à une position structurale, la götzenite étant le pôle calcique. Grâce à la substitution de $\mathrm{Zr}$ au Ti, une autre solution solide existe entre kochite et rosenbuschite, cette dernière étant le pôle zirconifère. La substitution $\mathrm{Ca} \rightarrow \mathrm{Zr}$ exerce un effet important sur la dimension des octaèdres respectifs, de même que sur la dimension et la distorsion des polyèdres adjacents. La réduction de la taille de l'octaèdre $\mathrm{Ca} \rightarrow \mathrm{Zr}$ serait en partie compensée par une augmentation de la taille des octaèdres adjacents contenant le Ti. Ce changement favorise la substitution $\mathrm{Ti} \rightarrow \mathrm{Zr}$ à ce site. Des degrés différents de distorsion du groupe sorosilicaté et des octaèdres adjacents contenant le Ca et le

§ E-mail address: claesc@savik.geomus.ku.dk 
Na sont aussi associés à la substitution $\mathrm{Ca} \rightarrow \mathrm{Zr}$. La seidozerite, riche en $\mathrm{Zr}$, montre un empilement des séquences stratifiées $H O H$ différent de celui des structures mentionnées ci-haut. Ce changement est étroitement lié aux interrelations géométriques complexes entre dimensions et distorsions des octaèdres à dominance de $\mathrm{Zr}$ et de $\mathrm{Mn}$. Les données chimiques indiquent que la seidozerite ne forme pas de solution solide avec la rosenbuschite.

(Traduit par la Rédaction)

Mots-clés: groupe de la rosenbuschite, seidozerite, cristallochimie, diffraction X sur monocristal, données à la microsonde électronique, degré d'ordre des cations, géométrie des polyèdres.

\section{INTRODUCTION}

The rosenbuschite group of minerals are $\mathrm{Ca}$ - and $\mathrm{Na}$ containing zirconium and titanium silicates occurring mainly as accessory phases in Si-undersaturated alkaline and in calc-alkaline rocks. They are sorosilicates composed of a framework of corner- and edge-sharing polyhedra and rows of $\mathrm{Si}_{2} \mathrm{O}_{7}$ groups. The polyhedra containing the 6- to 8-coordinated cations combine into layers ( $O$ layers) and into ribbons by edge sharing. Heterogeneous layers ( $H$ layers), composed of the octahedra from the ribbons and the sorosilicate groups, alternate with the $O$ layer into a layered $\mathrm{HOH}$ structure. The minerals contain a wide variety of elements, $\mathrm{Na}$, $\mathrm{Mg}, \mathrm{Ca}, \mathrm{Ti}, \mathrm{Mn}, \mathrm{Fe}, \mathrm{Y}, \mathrm{Zr}, \mathrm{Nb}$ and the rare-earth elements (REE), which are distributed over the 6- to 8-coordinated cation positions.

We have chemically analyzed a series of rosenbuschite-group minerals from the localities of Werner Bjerge, East Greenland (sample WBC-12 and WBC13) and Langesund Fjord, Norway (sample LF-A2 and LF-A5). Included in the study also is seidozerite from the Lovozero Complex, Kola Peninsula in Russia (sample 1993.158 from the collection of the Geological Museum of Copenhagen). During the study, doubt arose on the definition of the mineral rosenbuschite, and the type material (sample no. TYROS) described by Brögger (1889) was subsequently included in this work (kindly provided to us by Dan Holtstam from the Museum of Natural History in Stockholm, collection number \#531136). We established the chemical compositions of all specimens using an electron microprobe. On that basis, five specimens were chosen for further investigation by means of single-crystal X-ray diffraction.

We offer a detailed description of the cation distribution within the rosenbuschite group and detailed crystal-chemical comparisons of the specimens investigated. We intend to describe and explain the crystal-chemical implications of the substitutions taking place within the group. We concentrate on geometrical properties of the individual coordination polyhedra, set in relation to the overall topology and the cation distribution within each specimen. This approach enables us to provide qualitative arguments concerning the degree of solid solution among the members of the group. Furthermore, seidozerite is introduced as a member of the rosen- buschite group by describing its polytypic relationship to the other members of the group. Finally, we relate the existence of the two configurational polytypes to their different chemical compositions.

\section{BACKGROUND INFORMATION}

The group, named after the mineral rosenbuschite, was first described by Brögger in 1887. Thereafter, a number of minerals were suggested to be related to rosenbuschite (Brögger 1889, 1890, Blumrich 1893, Zachariasen 1930, Peacock 1937, Neumann 1962, Sahama et al. 1966). It was not until the structure solutions of seidozerite (Simonov \& Belov 1960, Skszat \& Simonov 1966) and rosenbuschite (Shibaeva et al. 1964) that the group could be defined on a structural basis. At present, the group comprises the minerals götzenite (Sahama \& Hytönen 1957, Cannillo et al. 1972), hainite (Blumrich 1893, Johan \& Čech 1989, Rastsvetaeva et al. 1995, Atencio et al. 1999), rosenbuschite (Brögger 1890) and a new phase, kochite (Christiansen et al. 2003), which was discovered in relation to the present work. We include seidozerite (Semenov et al. 1958) as a member of the rosenbuschite group because its crystal structure is polytypically related to the minerals of this group (Egorov-Tismenko \& Sokolova 1990, Christiansen et al. 1999), and the elements contained in seidozerite are also major components in other members of the group. The polytypic layer is the so-called $\mathrm{HOH}$ layer characteristic for the plesiotypic family of heterophyllosilicates (Ferraris et al. 1996, Ferraris 1997, Christiansen et al. 1999). Bafertisite, perraultite, lamprophyllite, and delindeite are all sorosilicate members of this series that have a plesiotypic (Makovicky 1997) relationship to the members of the rosenbuschite group in that the coordination of certain elements differs. The minerals dealt with in this work all have the same coordination of atoms in corresponding positions.

Recently, rosenbuschite-group minerals from different environments have been analyzed by Bulakh \& Kapustin (1973), Cundari \& Ferguson (1994), Sharygin et al. (1996), Atencio et al. (1999) and Men'shikov et al. (1999). It has become apparent to us that the group has a wide chemical variation with respect to the elements hosted within the framework of octahedra. Especially important in this aspect is the replacement of $\mathrm{Ca}$ by $\mathrm{Zr}$ in one atomic position. Cannillo et al. (1972) 
raised the question of an isomorphous series, with götzenite and seidozerite as the two end-members. These two minerals represent the $\mathrm{Zr}$-poor and $\mathrm{Zr}$-rich members of the group, respectively, and rosenbuschite would be an intermediate member. A less extensive series between götzenite and rosenbuschite, with hainite as an intermediate member, has also been suggested by Johan \& Čech (1989). Substitution schemes for such series have been worked out purely on the basis of chemical composition and charge considerations (Johan \& Čech 1989, Cundari \& Ferguson 1994, Sharygin et al. 1996). However, a replacement of Ca by $\mathrm{Zr}$ does not only affect charge balance but, owing to the quite different ionic radii of the two elements, also causes a reduction in the size of the coordination octahedron. This reduction will affect the geometry of the surrounding coordination polyhedra. However, no analysis of these aspects has yet been conducted.

The general formula $(M 1)_{4}(M 2)_{4}(M 3)_{4}(M 4)_{2}(M 5)_{2}$ $\left(\mathrm{Si}_{2} \mathrm{O}_{7}\right)_{4} \mathrm{~F}_{4} X_{4}(M=\mathrm{Na}, \mathrm{Mg}, \mathrm{Ca}, \mathrm{Ti}, \mathrm{Mn}, \mathrm{Fe}, \mathrm{Y}, \mathrm{Zr}, \mathrm{Nb}$, and the rare-earth elements, REE, and $X=\mathrm{O}, \mathrm{F}$ ) may be taken to represent all members of the rosenbuschite group. Taking into consideration cation ordering at the $M$ positions and the topological variants in the group, we will show that the simplified chemical formulae of the five members may be given as: götzenite $\mathrm{Ca}_{2}(\mathrm{Ca}$, $\mathrm{Na})_{2} \mathrm{Ca}_{2} \mathrm{NaTi}\left(\mathrm{Si}_{2} \mathrm{O}_{7}\right)_{2} \mathrm{~F}_{2} \mathrm{~F}_{2}$, hainite $(\mathrm{Ca}, \mathrm{Zr}, \mathrm{Y})_{2}(\mathrm{Na}, \mathrm{Ca})_{2}$ $\mathrm{Ca}_{2} \mathrm{NaTi}\left(\mathrm{Si}_{2} \mathrm{O}_{7}\right)_{2} \mathrm{~F}_{2} \mathrm{~F}_{2}$, kochite $\mathrm{Zr}_{2}(\mathrm{Mn}, \mathrm{Zr})_{2}(\mathrm{Na}, \mathrm{Ca})_{4}$ $\mathrm{Ca}_{4} \mathrm{Na}_{2} \mathrm{Ti}_{2}\left(\mathrm{Si}_{2} \mathrm{O}_{7}\right)_{4} \mathrm{~F}_{4} \mathrm{O}_{4}$, rosenbuschite $\mathrm{Zr}_{2} \mathrm{Ca}_{2}(\mathrm{Na}, \mathrm{Ca})_{4}$
$\mathrm{Ca}_{4} \mathrm{Na}_{2} \mathrm{ZrTi}\left(\mathrm{Si}_{2} \mathrm{O}_{7}\right)_{4} \mathrm{~F}_{4} \mathrm{O}_{4}$, and seidozerite $\mathrm{Zr}_{4} \mathrm{Na}_{2} \mathrm{Mn}_{2}$ $\mathrm{Na}_{4} \mathrm{Na}_{2} \mathrm{Ti}_{2}\left(\mathrm{Si}_{2} \mathrm{O}_{7}\right)_{4} \mathrm{~F}_{4} \mathrm{O}_{4}$.

\section{EXPERIMENTAL WORK}

Chemical analyses were conducted on a JEOL 733 electron microprobe using Tracor Northern 5500 and 5600 automation in wavelength-dispersion mode. The electron beam was accelerated over $20 \mathrm{kV}$ with a beam current of $20 \mathrm{nA}$ and had a diameter of $20 \mu \mathrm{m}$. Data reduction was performed using a PAP routine in XMAQNT (C. Davidson, CSIRO, pers. commun.). The following standards were used: vlasovite $(\operatorname{Zr} L \alpha)$, tephroite $(\mathrm{Mn} K \alpha)$, albite $(\mathrm{Na} K \alpha)$, diopside $(\mathrm{Mg} K \alpha)$, almandine $(\mathrm{Si} K \alpha, \mathrm{Fe} K \alpha), \mathrm{MnNb}_{2} \mathrm{O}_{6}(\mathrm{Nb} L \alpha)$, rutile $(\mathrm{Ti} K \alpha)$, celestine $(\mathrm{Sr} L \alpha)$, apatite $(\mathrm{P} K \alpha), \mathrm{TbPO}_{4}(\mathrm{~Tb} L \alpha)$, sanbornite $(\mathrm{Ba} L \alpha)$, YIG $(\mathrm{Y} L \alpha), \mathrm{GdPO}_{4}(\mathrm{Gd} L \alpha)$, hafnon $(\mathrm{Hf} M \alpha), \mathrm{LaPO}_{4}(\mathrm{La} L \alpha), \mathrm{CoWO}_{4}(\mathrm{~W} M \alpha), \mathrm{EuPO}_{4}$ $(\mathrm{Eu} L \alpha)$, chrysoberyl $(\mathrm{Al} K \alpha), \mathrm{NiTa}_{2} \mathrm{O}_{6}(\mathrm{Ta} M \alpha), \mathrm{CePO}_{4}$ $(\mathrm{Ca} L \alpha), \mathrm{SmPO}_{4}(\mathrm{Sm} L \alpha)$, zincite $(\mathrm{Zn} L \alpha)$, rubidium-substituted microcline $(\mathrm{Ru} L \alpha), \mathrm{NdPO}_{4}(\mathrm{Nd} L \alpha), \mathrm{VPO}_{4}$ $(\mathrm{V} K \alpha)$, phlogopite $(\mathrm{F} K \alpha)$, pollucite $(\mathrm{Cs} L \alpha), \mathrm{PrPO}_{4}$ $(\operatorname{Pr} L \alpha), \mathrm{ErPO}_{4}(\mathrm{Er} L \alpha), \mathrm{REE}-$ bearing glass $(\mathrm{Sc} K \alpha)$, $\mathrm{TmPO}_{4}(\mathrm{Tm} L \alpha)$, cassiterite $(\operatorname{Sn} L \alpha), \mathrm{DyPO}_{4}(\mathrm{Dy} L \alpha)$, $\mathrm{YbPO}_{4}(\mathrm{Yb} L \alpha)$, sanidine $(\mathrm{K} K \alpha)$. Empirical formulae were calculated on the basis of eight atoms of $\mathrm{Si}$ in agreement with the structure refinements, which invariably show fully occupied silicon positions. Chemical data for the selected specimens are given in Table 1.

TABLE 1. CHEMICAL COMPOSITIONS AND FORMULA UNITS OF MEMBERS OF THE ROSENBUSCHITE GROUP

\begin{tabular}{|c|c|c|c|c|c|c|c|c|c|c|c|c|}
\hline \multirow[t]{2}{*}{$\begin{array}{l}\text { Sample } \\
\text { Mineral }\end{array}$} & \multicolumn{2}{|c|}{$\begin{array}{c}\text { WBC-13 } \\
\text { Götzenite }\end{array}$} & \multicolumn{2}{|c|}{$\begin{array}{l}\text { WBC-12 } \\
\text { Kochite }\end{array}$} & \multicolumn{2}{|c|}{$\begin{array}{l}\text { LF-A2 } \\
\text { Hainite }\end{array}$} & \multicolumn{2}{|c|}{$\begin{array}{c}\text { LF-A5 } \\
\text { Rosenbuschite }\end{array}$} & \multicolumn{2}{|c|}{$\begin{array}{c}\text { TYROS } \\
\text { Rosenbuschite }\end{array}$} & \multicolumn{2}{|c|}{$\begin{array}{c}1993.158 \\
\text { Seidozerite }\end{array}$} \\
\hline & wt. $\%$ & apfu ${ }^{*}$ & wt. $\%$ & apfu & wt. $\%$ & apfu & wt. $\%$ & apfu & wt. $\%$ & apfu & wt. $\%$ & apfu \\
\hline $\mathrm{SiO}_{2}$ & 30.85 & 8.00 & 31.19 & 8.00 & 30.50 & 8.00 & 29.94 & 8.00 & 30.51 & 8.00 & 30.73 & 8.00 \\
\hline $\mathrm{Al}_{2} \mathrm{O}_{3}$ & 0.05 & 0.02 & 0.05 & 0.02 & 0.05 & 0.02 & n.d. & & n.d. & & 0.08 & 0.02 \\
\hline $\mathrm{TiO}_{2}$ & 9.24 & 1.80 & 8.42 & 1.62 & 8.16 & 1.61 & 4.56 & 0.92 & 6.83 & 1.35 & 13.88 & 2.72 \\
\hline $\mathrm{SnO}_{2}$ & n.d.** & & n.d. & & n.d. & & 0.19 & 0.02 & n.d. & & n.d. & \\
\hline $\mathrm{ZrO}_{2}^{2}$ & 1.41 & 0.18 & 11.90 & 1.49 & 3.96 & 0.51 & 19.66 & 2.56 & 15.86 & 2.03 & 21.83 & 2.77 \\
\hline $\mathrm{HfO}_{2}$ & n.d. & & 0.09 & 0.01 & 0.08 & 0.01 & 0.46 & 0.04 & 0.34 & 0.03 & 0.38 & 0.03 \\
\hline $\mathrm{Nb}_{2} \mathrm{O}_{5}$ & 1.12 & 0.13 & 1.85 & 0.21 & 1.23 & 0.15 & 1.35 & 0.16 & 2.25 & 0.27 & 0.77 & 0.09 \\
\hline $\mathrm{Ta}_{2} \mathrm{O}_{5}$ & n.d. & & 0.02 & 0.00 & 0.03 & 0.00 & 0.11 & 0.01 & 0.06 & 0.00 & 0.01 & 0.00 \\
\hline $\mathrm{MgO}$ & n.d. & & 0.01 & 0.00 & n.d. & & 0.06 & 0.02 & n.d. & & 1.53 & 0.59 \\
\hline $\mathrm{MnO}$ & 1.04 & 0.23 & 4.92 & 1.07 & 0.73 & 0.16 & 0.91 & 0.21 & 1.08 & 0.24 & 3.86 & 0.85 \\
\hline $\mathrm{FeO}$ & 0.44 & 0.10 & 1.08 & 0.2 & 0.69 & 0. & 0.50 & 0.11 & 0.28 & 0. & 2.93 & 0.64 \\
\hline $\mathrm{CaO}$ & 36.70 & 10.20 & 21.39 & 5.8 & 29.64 & 8. & 23.40 & 6.70 & 24.54 & & 6 & 0.52 \\
\hline $\mathrm{SrO}$ & 0.18 & 0.03 & 0.12 & 0.0 & 0.08 & 0.01 & 0.14 & 0.02 & 0. & 0.02 & 0.19 & 0.03 \\
\hline $\mathrm{Na}_{2} \mathrm{O}$ & 6.31 & 3.17 & 9.85 & 4.9 & 7.45 & 3.79 & 9.16 & 4.7 & 9.47 & 4.81 & 14.69 & 7.41 \\
\hline $\mathrm{Y}_{2} \mathrm{O}_{3}$ & 0.90 & 0.12 & 0.38 & 0.05 & 4.35 & 0.61 & 1.00 & 0.14 & 1.28 & 0.18 & 0.19 & 0.03 \\
\hline $\mathrm{La}_{2} \mathrm{O}_{3}$ & 1.66 & 0.16 & 0.24 & 0.02 & 0.63 & 0.06 & n.d. & & n.d. & & n.d. & \\
\hline $\mathrm{Ce}_{2} \mathrm{O}_{3}$ & 2.71 & 0.26 & 0.57 & 0.05 & 1.67 & 0.16 & 0.13 & 0.01 & 0.17 & 0.02 & n.d. & \\
\hline $\mathrm{Nd}_{2} \mathrm{O}_{3}$ & 0.44 & 0.04 & n.d. & & 0.71 & 0.07 & n.d. & & n.d. & & n.d. & \\
\hline $\mathrm{Gd}_{2} \mathrm{O}_{3}$ & 0.39 & 0.03 & n.d. & & 0.20 & 0.02 & n.d. & & n.d. & & n.d. & \\
\hline $\mathrm{Dy}_{2} \mathrm{O}_{3}$ & n.d. & & n.d. & & 0.98 & 0.08 & n.d. & & n.d. & & n.d. & \\
\hline $\mathrm{Er}_{2} \mathrm{O}_{3}$ & n.d. & & n.d. & & 0.59 & 0.05 & n.d. & & n.d. & & n.d. & \\
\hline $\mathrm{Yb}_{2} \mathrm{O}_{3}$ & n.d. & & n.d. & & 0.74 & 0.06 & n.d. & & 0.08 & 0.01 & n.d. & \\
\hline & 8.60 & 7.05 & 6.70 & 5.43 & 7.81 & 6.48 & 7.15 & 6.04 & 6.72 & 5.57 & 4.59 & 3.78 \\
\hline $\mathrm{O}=\mathrm{F}$ & -3.62 & & -2.82 & & -3.29 & & -3.01 & & 2.8 & & -1.93 & \\
\hline $\mathrm{O}$ & & 29.84 & & 29.92 & & 29.67 & & 30.23 & & 30.61 & & 31.80 \\
\hline Total & 98.43 & & 95.95 & & 97.08 & & 95.84 & & 96.74 & & 95.58 & \\
\hline & $s^{* * *}$ & 36.90 & & 35.36 & & 36.15 & & 36.27 & & 36.1 & & 35.58 \\
\hline & $15 * * * * *$ & 16.45 & & 15.55 & & 15.88 & & 15.67 & & 15.90 & & 23.67 \\
\hline
\end{tabular}

* Calculated on the basis of $8 \mathrm{Si}$.** Not detected. *** Ideal sum is $36 . * * * *$ Ideal sum is 16. 
Crystals used for single-crystal X-ray measurements were selected after optical inspection in order to avoid grains containing multiple crystallites. The ranges of the largest and smallest dimensions of the investigated crystals were respectively 0.11 to $0.18 \mathrm{~mm}$ and 0.02 to $0.07 \mathrm{~mm}$. The crystals were mounted on a Bruker AXS four-circle diffractometer equipped with a CCD 1000K area detector and a flat graphite monochromator using $\mathrm{MoK \alpha}$ radiation from a fine-focus sealed X-ray tube. Reflections used for unit-cell determination were measured with long-duration exposures in search of weak superstructure reflections. This is an important aspect in identifying the different members of the group, since cation ordering may cause a doubling of the $b$ axis, as is seen in rosenbuschite. Unit-cell determination and data collection were done in the SMART system of programs. Using $\omega$ - and $\phi$-scans with a step size of $0.25^{\circ}$, intensities were measured for reflections within the $\theta$ range of $3.9^{\circ}$ and $35^{\circ}$. The data collection of sample \#531136 was done under different standard settings, and reflections were only measured for $\theta$ below $24^{\circ}$. Integrated intensities were calculated using the program SAINT. XPREP was used for unit-cell determination and calculation of intensities corrected for absorption. The $\left|E^{2}-1\right|$ value (Table 2) indicated all the triclinic structures to be centrosymmetric. However, Rastsvetaeva et al. (1995) found hainite (described as giannetite) to have crystallized in $P 1$, and our datasets were therefore processed in each of the space groups, and the structures were further refined. In all cases, no significant differences between the acentric and the centrosymmetric models were observed, and all structures were concluded to be in $P \overline{1}$. The symmetry of seidozerite is $P 2 /$ $n$ in accordance with Simonov \& Belov (1960). During the semiempirical absorption-corrections, crystal
1993.158 was modeled as a lamina parallel to (001), and the shape of the other crystals was fitted by an ellipsoid. Unit-cell dimensions and internal $R$-values after the corrections are given in Table 2.

\section{Refinement procedure}

Full-matrix least-squares refinements on $F^{2}$ were carried out in the SHELXL-97 program. Initial atom coordinates were taken from Cannillo et al. (1972) [götzenite], Shibaeva et al. (1964) [rosenbuschite] and Simonov \& Belov (1960) [seidozerite], and refined isotropically. Site-occupancy factors (s.o.f.) were refined for all cation positions (the so-called $M$ positions) except for the silicon positions. For atom positions on which the s.o.f. was found to differ significantly from unity after a first refinement, a weighted sum of X-ray scattering factors for two types of elements was used, and the sum of the two elements was constrained to be unity. All atoms were modeled anisotropically, and the s.o.f. for the $\mathrm{Si}, \mathrm{O}, \mathrm{F}$ positions were in turn set free, but all refined close to unity and were subsequently constrained to full occupancy. The distribution of $\mathrm{O}$ and $\mathrm{F}$ was estimated using bond-valence calculations and incorporated in a second refinement procedure. Finally, an isotropic secondary extinction was applied, but no improvement of the results was observed. Unit cells and statistical values for the refinements are given in Table 2. Refined atom coordinates for samples WBC-13, LFA5 and 1993.158, which represent the three structure variants of the group, are given in Table 3. Observed and calculated structure-factors for all samples have been submitted to the Depository of Unpublished Data, CISTI, National Research Council of Canada, Ottawa, Ontario K1A 0S2, Canada.

\begin{tabular}{|c|c|c|c|c|c|c|}
\hline $\begin{array}{l}\text { Mineral } \\
\text { Space group }\end{array}$ & $\begin{array}{c}\text { WBC-13 } \\
\text { Götzenite } \\
P \mathbb{1}\end{array}$ & $\begin{array}{l}\text { WBC-12 } \\
\text { Kochite } \\
P \overline{\bar{l}}\end{array}$ & $\begin{array}{c}\mathrm{LF}-\mathrm{A} 2 \\
\text { Hainite } \\
P \overline{1}\end{array}$ & $\begin{array}{c}\text { LF-A } 5 \\
\text { Rosenbuschite } \\
P \overline{1}\end{array}$ & $\begin{array}{c}\text { TYROS } \\
\text { Rosenbuschite } \\
P \overline{1}\end{array}$ & $\begin{array}{c}1993.158 \\
\text { Seidozerite } \\
P 2 / c\end{array}$ \\
\hline $\begin{array}{l}a(\AA) \\
b(\AA) \\
c(\AA) \\
\alpha\left({ }^{\circ}\right) \\
\beta\left({ }^{\circ}\right) \\
\gamma\left({ }^{\circ}\right)\end{array}$ & $\begin{array}{c}9.6192(7) \\
5.7249(4) \\
7.3307(5) \\
89.921(2) \\
101.132(2) \\
100.639(2)\end{array}$ & $\begin{array}{r}10.032(2) \\
11.333(2) \\
7.202(1) \\
90.192(4) \\
100.334(5) \\
111.551(4)\end{array}$ & $\begin{array}{c}9.6079(7) \\
5.7135(5) \\
7.3198(5) \\
89.916(2) \\
101.077(2) \\
100.828(2)\end{array}$ & $\begin{array}{c}10.137(2) \\
11.398(2) \\
7.2714(12) \\
90.216(3) \\
100.308(4) \\
111.868(4)\end{array}$ & $\begin{array}{c}10.108(1) \\
11.375(1) \\
7.2620(9) \\
90.165(4) \\
100.311(3) \\
111.911(3)\end{array}$ & $\begin{array}{c}5.5558(3) \\
7.0752(4) \\
18.406(1) \\
102.713(1)\end{array}$ \\
\hline $\begin{array}{l}\mathrm{N}_{\text {coll. }}{ }^{*} \\
\mathrm{R}_{\text {int }} \\
\text { Data } \\
\text { Parameters } \\
\left|E^{2}-1\right| \\
R(\mathrm{~F}) \\
w R\left(\mathrm{~F}^{2}\right)^{* *} \\
\text { Goof*** } \\
\Delta \rho_{\max } \\
\Delta \rho_{\min }\end{array}$ & $\begin{array}{c}5448 \\
0.040 \\
3005 \\
145 \\
1.064 \\
4.0 \\
8.5 \\
1.014 \\
0.84 \\
-1.57\end{array}$ & $\begin{array}{c}9277 \\
0.036 \\
5529 \\
287 \\
1.272 \\
4.0 \\
7.8 \\
1.027 \\
0.93 \\
-1.11\end{array}$ & $\begin{array}{c}4459 \\
0.039 \\
2283 \\
144 \\
1.060 \\
3.7 \\
8.1 \\
1.016 \\
0.88 \\
-0.78\end{array}$ & $\begin{array}{c}11647 \\
0.056 \\
5895 \\
287 \\
1.190 \\
4.9 \\
8.5 \\
1.045 \\
1.34 \\
-0.94\end{array}$ & $\begin{array}{c}4833 \\
0.045 \\
2174 \\
287 \\
1.268 \\
3.2 \\
8.2 \\
1.002 \\
0.61 \\
-0.47\end{array}$ & $\begin{array}{c}7866 \\
0.044 \\
2099 \\
144 \\
1.067 \\
2.7 \\
6.5 \\
1.066 \\
0.56 \\
-1.05\end{array}$ \\
\hline
\end{tabular}

${ }^{*}$ Number of reflections collected. ${ }^{* *} R(\mathrm{~F})$ for $\mathrm{F}_{0}>4 \sigma \mathrm{F}_{0}, w R\left(\mathrm{~F}^{2}\right)$ for all data. *** Goodness of fit. 


\section{Site-assignment procedure}

The models of cation distributions presented here are based on chemical composition and refined site-scattering values. In the site-assignment procedure, all atom positions are assumed to be fully occupied, and the electron density of the assigned mixed occupancy has to equal the site-scattering values (expressed in electrons per formula units, epfu). In an iterative process, trial values were assigned to the occupancies (in atoms per formula unit, apfu), and the resulting models were evaluated using three distinct criteria:

1) A comparison of the composition of the model with the empirical formula. It should be noted that two distinct crystals were used for the chemical analysis and the analysis of the structure, respectively, and these may show minor differences.

2) A weighted bond-valence sum (BVS) was calculated for each site (parameters used are from Breese $\&$ O'Keeffe 1991) and compared with the corresponding valence-sum (VS).

3) Furthermore, a weighted ideal bond-length was calculated for each cation polyhedron using the ionic radii given by Shannon (1976) and compared with the average bond-length.
On the basis of present data, it is not possible to distinguish between the light and heavy rare-earth elements, and they are assigned using a weighted mean atomic number, but the bond-valence parameter and ionic radius of $\mathrm{Ce}$ were chosen as being representative of the observed REE mean. The results are given in Table 4.

Fluorine and oxygen are distributed over nine crystallographically distinct positions in götzenite, hainite and seidozerite, and 18 in rosenbuschite and kochite. The site assignment was guided by bond-valence calculations summarized in Table 5. The calculation indicated that all anion positions bonded to silicon (O1 to $O 7)$ are fully occupied by oxygen, and $F 9$ is fully occupied by fluorine. $X 8$ is a mixed oxygen-fluorine site, and the ratio between the anions on these sites is determined by the best fit between BVS and VS.

\section{CRystallography}

\section{General description of the crystal structure of götzenite and hainite}

The crystal structure of götzenite is triclinic (Fig. 1). In principle, the structure is a framework of edge- and

TABLE 3. ATOM COORDINATES AND ISOTROPIC TEMPERATURE-FACTORS FOR SAMPLES WBC-13, LF-A5 AND 1993.158

\begin{tabular}{|c|c|c|c|c|c|c|c|c|c|c|c|}
\hline site & & $x$ & $y$ & $z$ & $\mathrm{U}_{\text {iso }}$ & site & $N$ & $x$ & $y$ & $z$ & $\mathrm{U}_{\mathrm{iso}}$ \\
\hline \multirow{2}{*}{\multicolumn{6}{|c|}{ WBC-13 götzenite }} & $O$ & 2 & (4) & (3) & $0.3066(5)$ & $0.0175(8)$ \\
\hline & & & & & & & & & & $\begin{array}{l}360(5) \\
846(5)\end{array}$ & \\
\hline 2 & 2 & דגותו & $0.4966(1)$ & & & $O 3 \mathrm{~b}$ & 2 & $0.4024(4)$ & $533(3)$ & $0.8609(5)$ & 0.019 \\
\hline$M 3$ & 2 & $0.63285(6)$ & $0.2274(1)$ & 0.4074 & $0.0168(2)$ & $O 4 a$ & 2 & $0.3650(4)$ & $0.9166(3)$ & $0.3357(5)$ & $0.0249(9)$ \\
\hline$M 4$ & 1 & 0 & 0 & 0.5 & $0.0153(4)$ & $O 4 \mathrm{~b}$ & 2 & $0.3585(4)$ & $0.4096(3)$ & $0.3020(5)$ & $0.0249(9)$ \\
\hline M5 & 1 & 0 & 0 & 0 & & $05 a$ & 2 & $0.3452(4)$ & $0.9064(3)$ & $0.8387(5)$ & $3(9)$ \\
\hline$S_{i 1}$ & 2 & $688(8)$ & $94(1)$ & $9(1)$ & $1(1)$ & $O 5 \mathrm{~b}$ & 2 & $144(4)$ & $984(3)$ & $0.8680(5)$ & 0.0 \\
\hline$i$ & 2 & & $51(1)$ & (i) & $4(1)$ & $06 a$ & 2 & (4) & & $0.2279(5)$ & $5(8)$ \\
\hline$O 1$ & 2 & 0.75 & $600(4)$ & 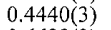 & 5) & $06 \mathrm{~b}$ & 2 & t) & 3) & 0.2 & (8) \\
\hline$O 2$ & 2 & $0.6152(2)$ & $0.9402(3)$ & .66 & & $O 7 \mathrm{a}$ & 2 & 3) & 0. & (5) & \\
\hline 03 & 2 & $0.6188(2)$ & $0.9363(3)$ & $0.1415(3)$ & $1(4)$ & $O 7 \mathrm{~b}$ & 2 & $0.1285(4)$ & $0.4799(3)$ & $0.8320(5)$ & 0.0 \\
\hline 04 & 2 & $0.6436(3)$ & $0.4773(4)$ & $.6670(3)$ & $0.0238(5)$ & $X 8 \mathrm{a}$ & 20 & $0.1308(3)$ & $0.1890(3)$ & $0.0365(4)$ & $6(7)$ \\
\hline 05 & 2 & & & & & $X 8 \mathrm{~b}$ & 20 & & & & \\
\hline 06 & 2 & & & & & $F 9 \mathrm{a}$ & 20 & & & & \\
\hline 07 & 2 & 0.88 & ) & ) & 0.01 & $F 9 \mathrm{a}$ & 20 & 0.121 & & & \\
\hline & 2 & $0.8852(2)$ & 0.2592 & 0.967 & 0.02 & & & & & & \\
\hline$F 9$ & & $0.8856(2)$ & $0.3062(3)$ & $0.4759(2)$ & 0.0 & \multicolumn{6}{|c|}{1993.158 seidozerite } \\
\hline \multirow{2}{*}{\multicolumn{6}{|c|}{ LF-A5 rosenbuschite }} & & & & & & \\
\hline & & & & & & & & & & & \\
\hline & & & & 0 & & $M 2 \mathrm{~b}$ & 2 & 0.5 & 0.8 & 0.25 & $38(4)$ \\
\hline & & 0.36 & 0.7 & 0.0 & 3) & $M B$ & 4 & $0.2020(2)$ & (1) & $0.06966(5)$ & $2(3)$ \\
\hline$M 2 \mathrm{a}$ & & $0.0056(2)$ & $0.2549(1)$ & (2) & 6) & $M 4$ & 2 & 0 & 0.8 & 0.25 & $57(4)$ \\
\hline & & 0.99 & $0.2524(1)$ & & & M5 & 2 & 0 & $8(7)$ & 0.2 & 0.0 \\
\hline & & 0.35 & 0.28 & 0.5 & & Sil & 4 & 0.7 & 0.3 & 0.1 & 0.00 \\
\hline & & 0.36 & $0.7925(1)$ & 0.58 & & $\mathrm{Si2}$ & 40 & & & & 0.0 \\
\hline & & 0 & 0 & 0. & & 01 & 4 & & & & \\
\hline$M 4$ & 1 & 0 & 0.5 & 0.5 & & $O_{2}$ & 4 & $0.9265(3)$ & $0.3211(2)$ & $3(8)$ & $0.0119(3)$ \\
\hline$M 5 \mathrm{a}$ & 1 & 0 & 0 & 0 & & 03 & 40 & $0.9022(3)$ & $0.9102(2)$ & & $0.0113(3)$ \\
\hline & & 0 & & 0 & & 04 & 4 & & $0.3188(2)$ & & \\
\hline & & 0.2 & ) & & & 05 & 40 & & (2) & 0.0 & 0.0 \\
\hline & & 0.28 & & & & 06 & 4 & & & 0.1 & \\
\hline & & 0.28 & 0.51 & & 0.0 & 07 & 4 & 0.820 & $36(2)$ & 0.18 & $0.0130(3)$ \\
\hline & & $0.2887(1)$ & $0.5092(1)$ & $0.7925(2)$ & $0.0123(3)$ & $X 8$ & 40 & $0.2364(3)$ & $0.1267(2)$ & $0.18400(9)$ & $0.0134(3)$ \\
\hline & & $0.2668(4)$ & $0.0320(4)$ & $0.5648(5)$ & $0.030(1)$ & $F 9$ & 4 & $0.3052(3)$ & $0.5767(2)$ & $0.19223(8)$ & $0.0224(3)$ \\
\hline$O 1 \mathrm{~b}$ & & $0.2659(4)$ & $0.4947(4)$ & $0.5640(5)$ & $0.035(1)$ & & & & & & \\
\hline
\end{tabular}




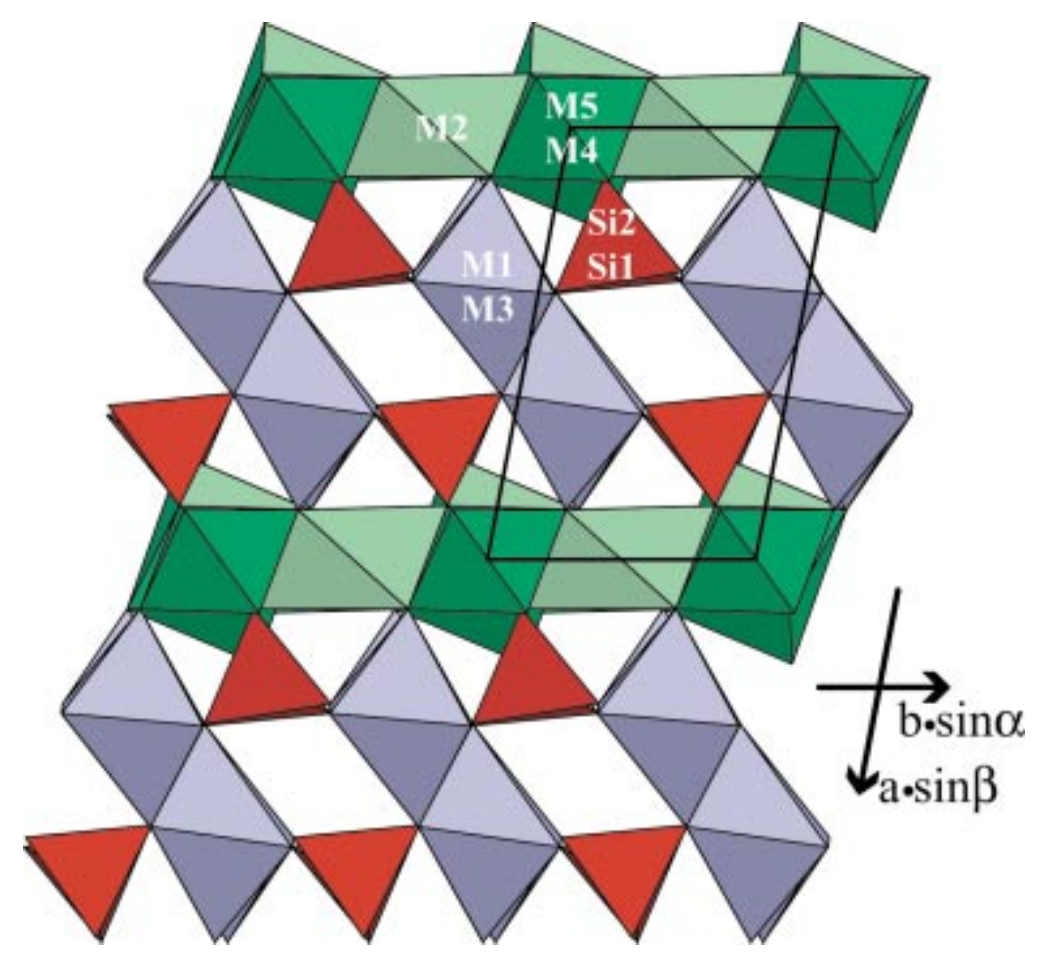

FIG. 1. The crystal structure of götzenite viewed along [001]. The cation positions are indicated.

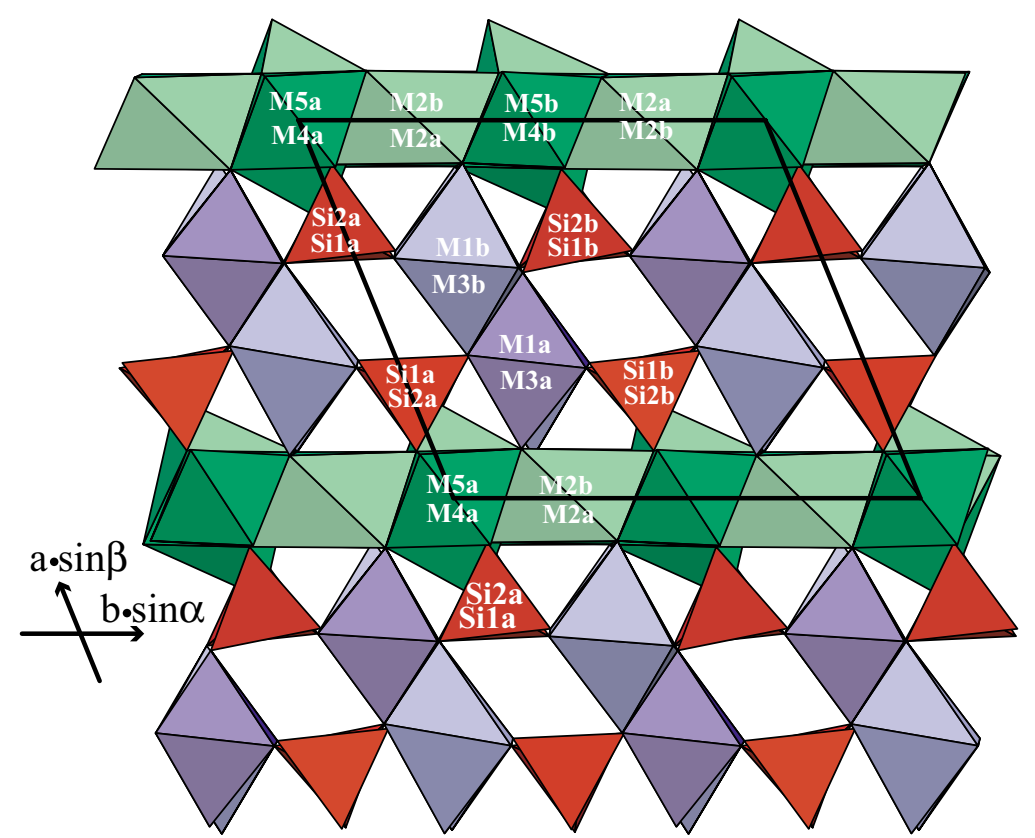

FIG. 2. The crystal structure of rosenbuschite (sample LF-A5) seen parallel to the $c$ axis. 
corner-sharing $M$ octahedra hosting a variety of cations. The edge-sharing octahedra combine into (100) layers and into [001] ribbons, which are interconnected by sharing polyhedron vertices. Sorosilicate groups are situated in the hollows of the framework, with one set of vertices in common with a layer of octahedra, and the other two sets shared with ribbons of octahedra.

The [001] ribbon contains one type of octahedron column, in which two distinct octahedra (M1 and $M 3$ ) alternate along the $c$ axis. Centers of symmetry located on the edges of these octahedra generate an adjacent column, and the ribbon is thus two octahedra wide. The layer of octahedra ( $O$ layer) is composed of two distinct
[001] columns. One contains only M2 octahedra mutually related by a center of inversion, and the other is composed of $M 5$ octahedra and $M 4$ polyhedra $(\mathrm{CN}=8)$, both of which are positioned on centers of symmetry.

\section{The double unit-cell of rosenbuschite and kochite}

As Cannillo et al. (1972) pointed out, rosenbuschite and götzenite are in principle isostructural. However, in rosenbuschite (Fig. 2), cation order in the $M 1$, and occasionally also in the $M 5$ positions, results in a unit cell doubled in comparison to that of götzenite, the unit-cell transformation matrix from götzenite to rosenbuschite

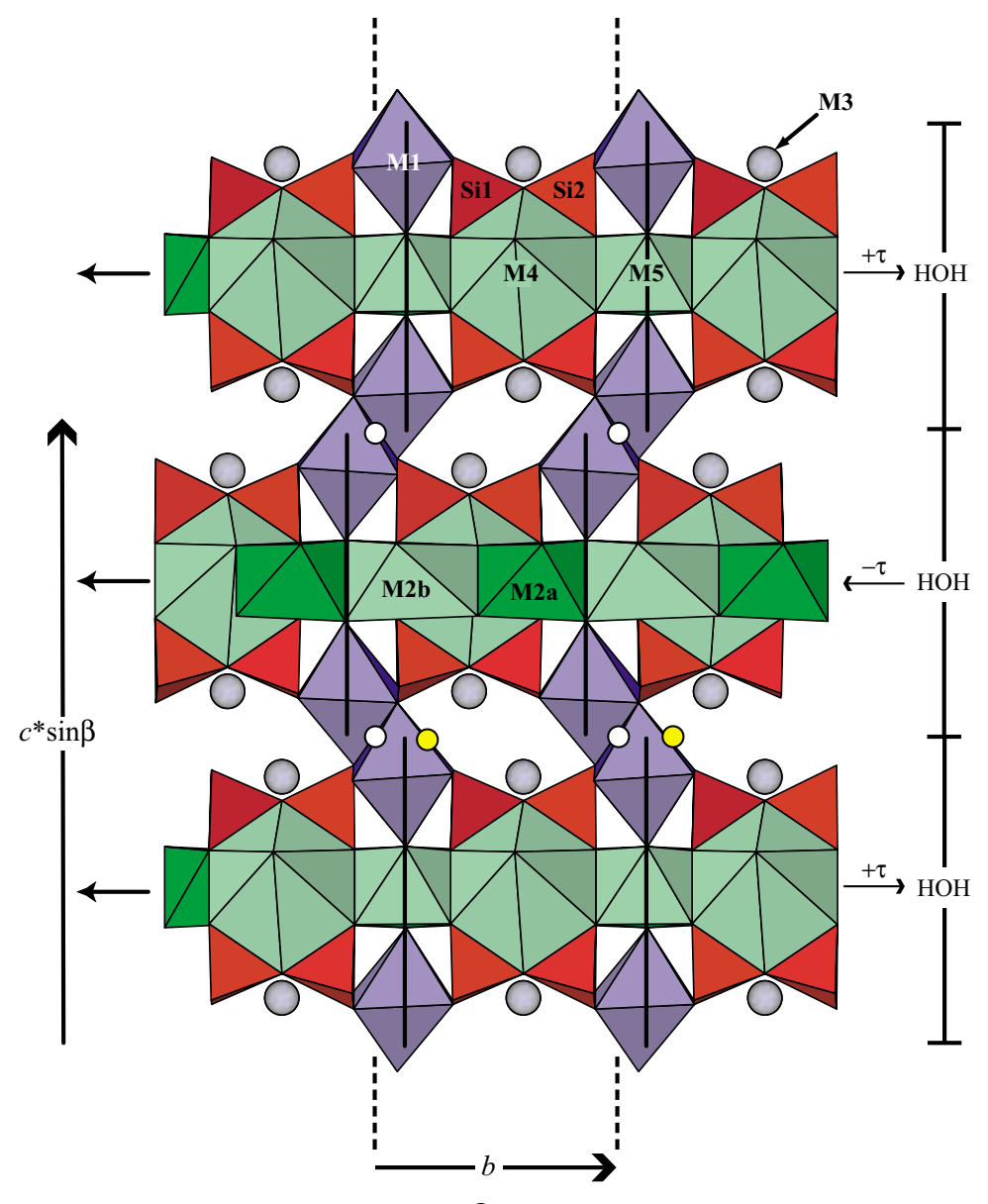

$\leftarrow$ twofold axis $\quad--n$ glide plane $\bigcirc$ center of inversion $\quad$ local mirror plane

FIG. 3. The crystal structure of the monoclinic seidozerite viewed parallel to the $a$ axis. The $H O H$ layers and stacking vectors $(\tau)$ are indicated to the right. Positions of relevant elements of symmetry in the whole structure are also indicated along with one set of the local mirror planes of the $\mathrm{HOH}$ layers. Coordination polyhedra around the $\mathrm{M} 3$ positions are not indicated. An alternative position to the center of symmetry relating the central and lower $\mathrm{HOH}$ layer is indicated in yellow, and represents the triclinic mode of stacking. 
being [ $-1-10$ / 0220 / $000-1]$. The symmetry remains $P \overline{1}$, but the double spacing between the centers of symmetry also doubles the number of crystallographically independent positions when compared to götzenite. Thus one position in götzenite corresponds to two in rosenbuschite, which in this work are indicated with suffixes a and $b$. In order to enhance the readability of this paper, these suffixes are left out in general, and are only indicated where a distinction between the relevant sites is needed.

Owing to the cation order at the $M 1$ positions, the ribbon of octahedra is not centrosymmetric, but is composed of two distinct columns of octahedra. The adjacent ribbons are related by centers of inversion, and the $\mathrm{a}$ and $\mathrm{b}$ columns are thus alternately positioned as the "upper" and "lower" column (Fig. 2). In the column composed of $M 2$ octahedra, no center of symmetry is present, and this column is thus composed of two crystallographically distinct octahedra. The two other columns are composed of $M 4 \mathrm{a}+M 5 \mathrm{a}$ and $M 4 \mathrm{~b}+M 5 \mathrm{~b}$ polyhedra, in which all central cations have site symmetry $\overline{1}$.

\section{The polytypic relationship to seidozerite}

The crystal structure of seidozerite (Fig. 3) is monoclinic. Owing to different axial settings, the $a$ axis of seidozerite corresponds to $b$ of götzenite and $b_{\text {seidozerite }}$

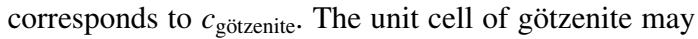
be transformed into that of seidozerite (approximately) by $[0 \quad 10 / 00-1 / / 2-1 / 2-1]$.

Christiansen et al. (1999) pointed out the polytypic relationship between götzenite-rosenbuschite and seidozerite. They are considered two maximally ordered polytypes in the configurational or heterochemical sense (Makovicky 1997) in that the chemical compositions of the minerals differ significantly. If one forgets about the chemical compositions, the two structures can be considered as stackings of identical $\mathrm{HOH}$ layers parallel to (001) (in the axial setting of seidozerite), as shown on Figure 3. The layers are bordered by planes cutting through the ribbons of octahedra, and each $\mathrm{HOH}$ layer is thus composed of an $O$ layer sandwiched between two heterogeneous layers ( $H$ layers) comprising the $\mathrm{Si}_{2} \mathrm{O}_{7}$ groups and $M(1,3)$ octahedra. The pseudosymmetry of

TABLE 4. SITE-SCATTERING VALUES (epfu), SITE ASSIGNMENT (apfu), COORDINATION NUMBER (CN), BOND-VALENCE* SUM (BVS), VALENCE SUM (VS), AVERAGE BOND-LENGTHS (ABL) AND IDEAL** BOND-LENGTHS (IBL) FOR ROSENBUSCHITE-GROUP MINERALS

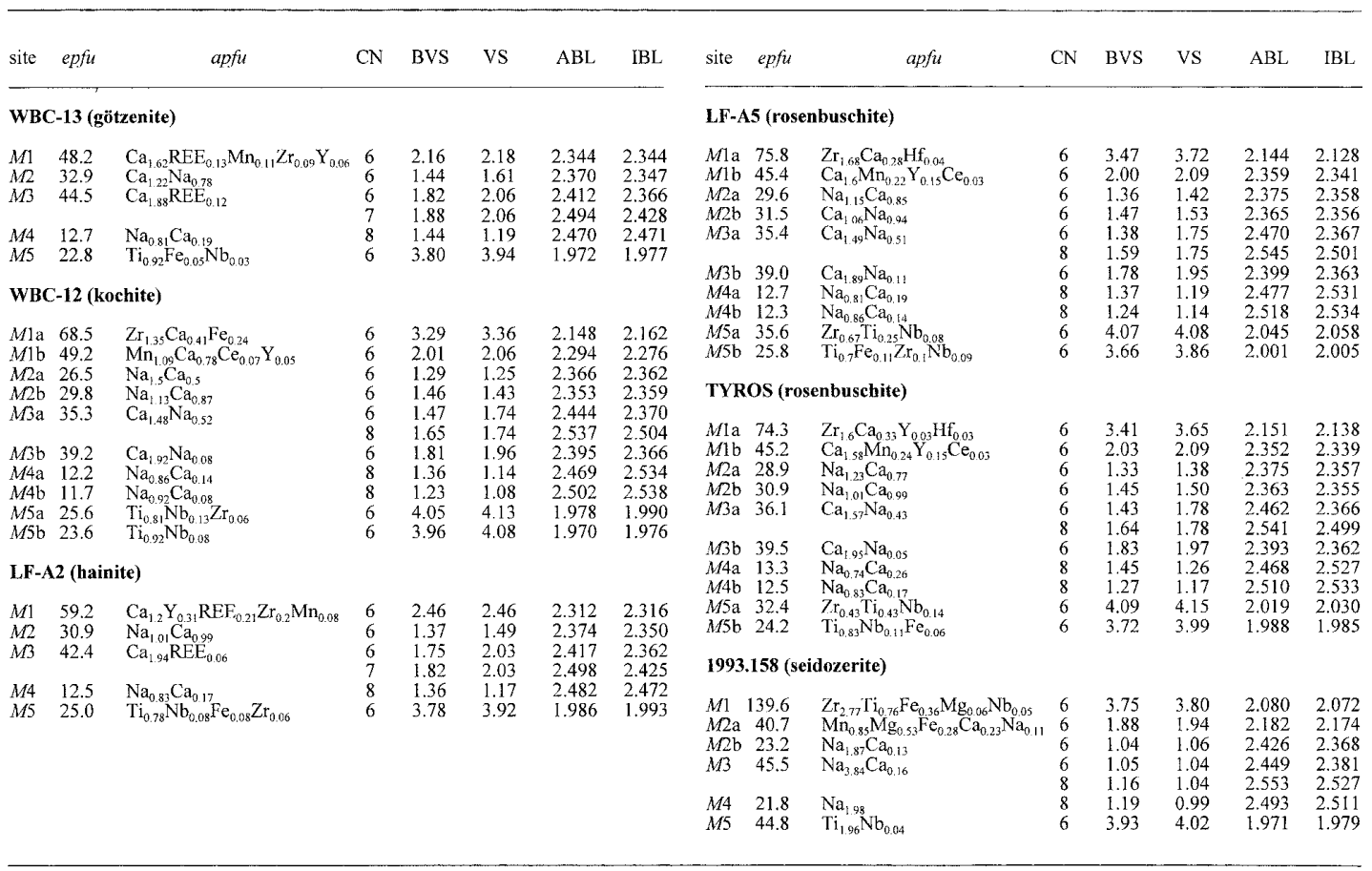

* Bond-valence parameters taken from Brese \& O'Keeffe (1991). **Ideal bond-lengths are calculated on the basis of the ionic radii of Shannon (1976). The bond lengths are quoted in $\AA$; epfu: electrons per formula unit, apfu: atoms per formula unit. 
the $\mathrm{HOH}$ layer is represented by the layer group $P 12 / m$ (1) with the two-fold axis parallel to $b$. On the boundary between the $M 1$ octahedra, the two adjacent layers are related by a center of inversion displacing them by $1 / 4 a+1 / 4 b(=\tau)$. The symmetry of the single $\mathrm{HOH}$ layer generates an alternative position for the interlayer center of inversion, located on the opposite side of the local mirror (Fig. 3). In this way, the center of inversion may, after each $\mathrm{HOH}$ layer, be located in one of these two positions, changing only the direction of shift $\tau$ of the following, adjacent $\mathrm{HOH}$ layer. The local mirror plane stands perpendicular to the $b$ axis, and it is only the $b$ component of $\tau$ that is affected. In götzenite, the directions of $\tau$ are uniform, and the stacking of layers can in this way be represented as $+\tau_{b}+\tau_{b}$. In this stacking sequence, the local centers of inversion of the $\mathrm{HOH}$ layer are consistent for the whole structure, and götzenite thus has triclinic symmetry. Seidozerite is characterized by a stacking sequence of $+\tau_{b}-\tau_{b}$, in which the local two-fold axes become total ones, resulting in monoclinic symmetry. In this structure, the local centers of inversion within the $\mathrm{HOH}$ layers become extinct as a result, resulting in two crystallographically distinct $M 2$ positions, situated on a two-fold axis $(M 2 \mathrm{a}$ and $M 2 \mathrm{~b}$ ). The $M 4$ and $M 5$ positions are also situated on a two-fold axis.

The present relationship has been described using the formalism for OD structures by Betti (1998) (S. Merlino, pers. commun.).

\section{Overview of the Distribution of Cations}

A graphical overview of the distribution of cations in the five specimens investigated is given in Figure 4. Each specimen represents a member in the rosenbuschite group (Table 4). Common to all members is the presence of sodium as the main occupant of the $M 4$ site.

In götzenite (WBC-13), $M 1, M 2$ and $M 3$ are all dominated by $\mathrm{Ca}$, and $\mathrm{Ti}$ occupies M5. Substantial amount of $\mathrm{Na}$ enters the $M 2$ position. In specimen LF$\mathrm{A} 2$, the $\mathrm{Na}$ :Ca ratio just exceeds 1 in this particular site,

TABLE 5. BOND-VALENCE SUMS FOR SILICON AND ANION POSITIONS IN ROSENBUSCHITE-GROUP SAMPLES

\begin{tabular}{|c|c|c|c|c|c|c|c|c|c|}
\hline \multirow{2}{*}{\multicolumn{2}{|c|}{$\begin{array}{r}\text { WBC-13 } \\
\text { götzenite } \\
\text { sitelsuffix }\end{array}$}} & \multicolumn{2}{|c|}{$\begin{array}{l}\text { WBC-12 } \\
\text { kochite }\end{array}$} & \multirow[t]{2}{*}{$\begin{array}{l}\text { LF-A2 } \\
\text { hainite }\end{array}$} & \multicolumn{2}{|c|}{$\begin{array}{c}\text { LF-A5 } \\
\text { rosenbuschite }\end{array}$} & \multicolumn{2}{|c|}{$\begin{array}{c}\text { TYROS } \\
\text { rosenbuschite }\end{array}$} & \multirow{2}{*}{$\begin{array}{c}1993.158 \\
\text { seidoz. } \\
a\end{array}$} \\
\hline & & $a$ & $b$ & & $a$ & $b$ & $a$ & $h$ & \\
\hline Sil vu & 4.01 & 4.05 & 4.04 & 4.00 & 4.03 & 3.98 & 4.08 & 4.02 & 4.03 \\
\hline & 4. & & 4.0 & & 4. & 3 & 4. & 4 & 4.03 \\
\hline$O 1$ & 2. & & 2.1 & 2. & 2.21 & 2. & 2.22 & 2. & 2.20 \\
\hline$O 2$ & 18 & & 10 & & 2.02 & 1. & 2.04 & 1.96 & 2.05 \\
\hline$O 3$ & 1. & & 1.8 & & 1. & & 1. & 1. & 1.92 \\
\hline$O 4$ & 1.8 & 1.8 & 1.87 & 1.86 & 1.83 & 1. & 1.88 & 1.86 & 1.93 \\
\hline 05 & & & & & & & 1. & & 2.02 \\
\hline 06 & 2. & 2. & 2.09 & 2. & 2.1 & 2. & 2.13 & 2.01 & 2.09 \\
\hline on & & & 2.07 & & 2.19 & & 2.20 & 2.03 & 2.14 \\
\hline$X 8^{*}$ & $\begin{array}{l}1.25 i \\
1.25\end{array}$ & $\begin{array}{l}1.60 / \\
1.7\end{array}$ & $\begin{array}{l}1.38 \% \\
1.5\end{array}$ & $1.31 /$ & 1.66 & $\begin{array}{l}1.36 / \\
1.4\end{array}$ & $\begin{array}{l}1.62 / \\
1.6\end{array}$ & $\begin{array}{l}1.37 / \\
1.4\end{array}$ & $\begin{array}{l}1.70 \prime \\
1.7\end{array}$ \\
\hline$F y$ & 0.96 & 1.02 & 0.99 & 0.96 & 1.01 & 0.98 & 1.04 & 1.03 & 0.98 \\
\hline
\end{tabular}

* Mixed site occupied by both oxygen and fluorine. The BVS/VS ratio is given. The results are expressed in valence units $(v u)$. Seidoz: seidozerite. whereas the remaining sites are dominated by the same cations. However, in the $M 1$ position, only $60 \%$ of the occupants are $\mathrm{Ca}$, because $\mathrm{Y}, \mathrm{REE}$ and $\mathrm{Zr}$ also enter this site. The overall $\mathrm{Na} / \mathrm{Ca}$ value of this specimen corresponds to that of hainite (Johan \& Čech 1989), and we therefore consider LF-A2 as hainite. In the work of Rastsvetaeva et al. (1995), ordering of the two cations at two crystallographically distinct $M 2$ positions causes a loss of centrosymmetry (see also Atencio et al. 1999). In the present work, no evidence of such order was observed. Samples WBC-13 and LF-A2 contain significant amounts of REE. This group of elements enters the $M 1$ and $M 3$ sites only. As pointed out by Christiansen \& Rønsbo (2000), the concentration of REE in these positions plays a key role in the relationship of götzenite to the closely associated and REE-rich rinkite group. This relationship is beyond the scope of this paper.

In rosenbuschite (LF-A5 and TYROS), substantial amounts of $\mathrm{Zr}$ enter one of the two $M 1$ positions, resulting in an ordering of $\mathrm{Ca}$ and $\mathrm{Zr}$. M1a in this way is dominated by $\mathrm{Zr}$, and $M 1 \mathrm{~b}$, by $\mathrm{Ca}$. Order involving Ti and $\mathrm{Zr}$ also is observed in the two M5 positions, in that M5a contain significant amounts of $\mathrm{Zr}$, and $M 5 \mathrm{~b}$ is occupied by Ti. In sample LF-A5, M5a is clearly dominated by $\mathrm{Zr}$, whereas the $\mathrm{Zr} / \mathrm{Ti}$ value equals 1 in the type-locality rosenbuschite (TYROS). The type material is therefore ambiguous in defining whether rosenbuschite is Ti- or $\mathrm{Zr}$-dominant in M5a. We recommend that rosenbuschite be considered $\mathrm{Zr}$-dominant at this site, because the $\mathrm{Zr}-\mathrm{Ti}$ order is observed in the type material of rosenbuschite, and a more advanced stage of this order is observed in specimen LF-A5.

In kochite (WBC-12), order at the $M 1$ sites similar to that in rosenbuschite is observed. In this mineral, $\mathrm{Zr}$ also dominates the $M 1$ a site, whereas $\mathrm{Mn}$ and $\mathrm{Ca}$ enter the $M 1 \mathrm{~b}$ site, with $\mathrm{Mn}$ as the dominant element. Kochite differs furthermore from sample LF-A5 and TYROS in that $\mathrm{Ti}$ is by far the dominant element at M5a.

The cation distributions in the remaining $M 2$ and $M 3$ sites are similar in all the variants of the rosenbuschite structure. Calcium is dominant at both the $M 3 \mathrm{a}$ and $M 3 \mathrm{~b}$ sites. However, $25 \%$ of the $M 3$ a site is occupied by Na (Table 4), whereas $M 3 \mathrm{~b}$ is fully occupied by $\mathrm{Ca}$. In the $M 2$ sites, the $\mathrm{Na} / \mathrm{Ca}$ values are all close to one, except for the $M 2 \mathrm{a}$ in sample WBC-12, which contains $75 \%$ Na.

In seidozerite (1993.158), no cation order is observed at $M 1$, and the site is dominated by $\mathrm{Zr}$, with $\mathrm{Ti}$ and $\mathrm{Fe}$ as important substituents. Like kochite, seidozerite contains a Mn-dominant site. However, in seidozerite, $\mathrm{Mn}$ enters the M2a site, which also hosts minor amounts of $\mathrm{Mg}$ and Fe. Unlike the other members of the group, seidozerite is very poor in $\mathrm{Ca}$. This is compensated for by a high content of $\mathrm{Na}$, which is distributed over the $M 2 \mathrm{~b}$ and $M 3$ sites in addition to the M4 site. The M5 site is occupied by Ti. These results is in good agreement with the cation distribution found in a different specimen of seidozerite by Pushcharovskii et al. (2002) except for the $M 2 \mathrm{~b}$ position, which in their specimen is dominated by $\mathrm{Ca}$. 
Götzenite
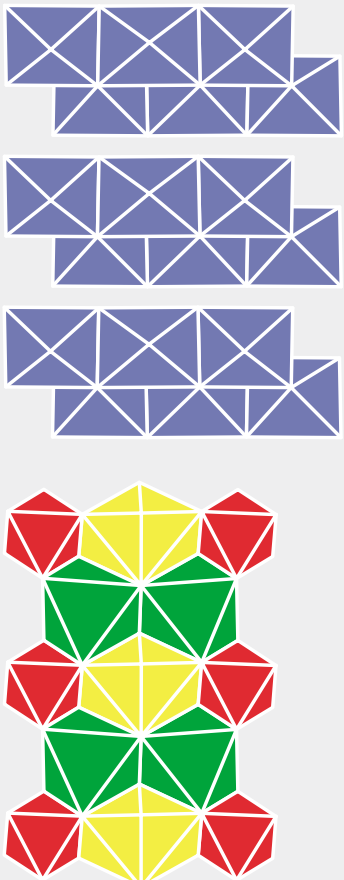

Rosenbuschite
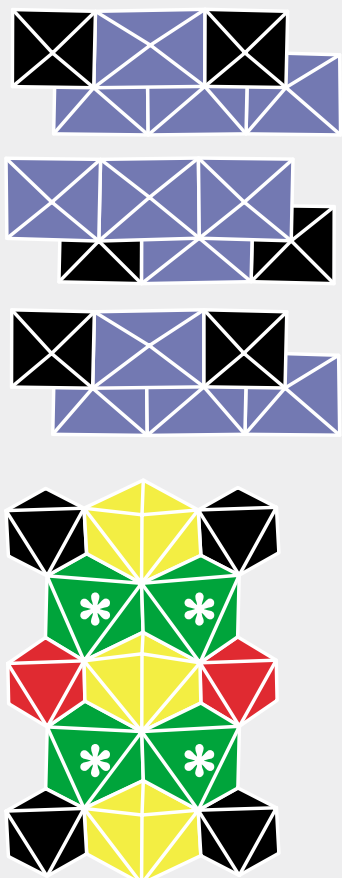

Hainite
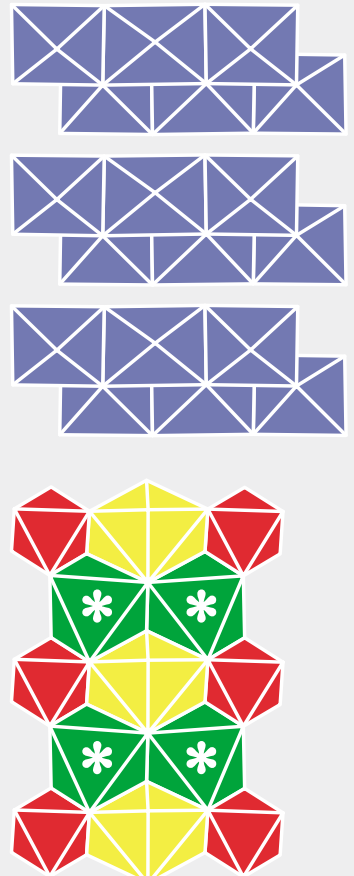

Seidozerite
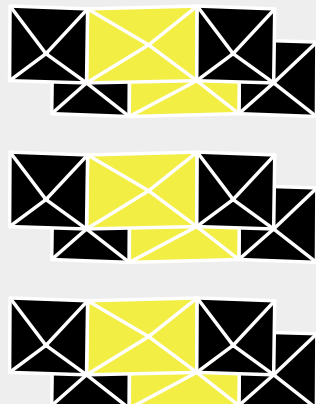

1

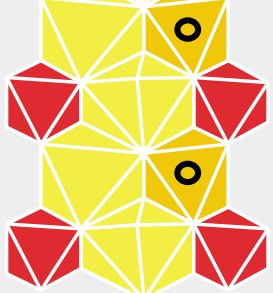

Kochite
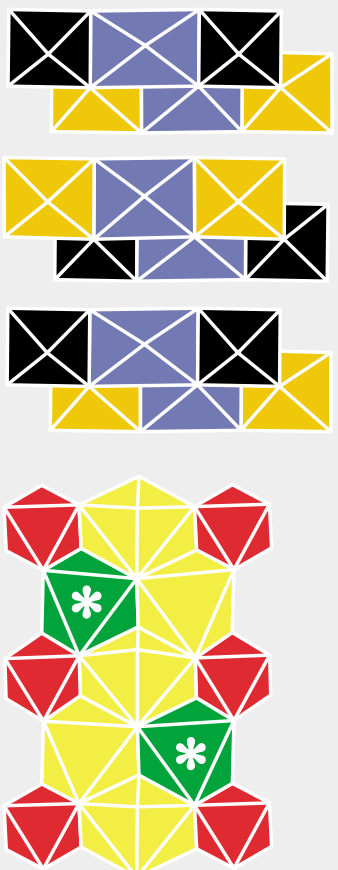


\section{DisCUSSION OF THE SITES}

The variety of cations occupying the $M$ positions in the rosenbuschite group of minerals have quite different ionic radii and valences. These cations are accommodated in coordination polyhedra of considerable differences in sizes and bond strengths. In order to

FIG. 4. The distribution of cations within the ribbons of octahedra (upper) and the layer of octahedra (lower) for the specimens of the rosenbuschite group investigated. The cation occupancies are represented by differently colored polyhedra. The setting of the figure corresponds to Figure 5. The scheme is inspired by Cannillo et al. (1972). combine these octahedra into edge-sharing ribbons and layers, a misfit between their ideal dimensions must be compensated for. In Table 6, a distortion parameter $(v)$ is given for each polyhedron. This parameter is defined as the deviation from the volume of an ideal polyhedron in percent (Makovicky \& Balić-Žunić 1998). Not surprisingly, the relatively small and strongly bonded $\mathrm{Si}$ tetrahedra and $\mathrm{Ti}$ and $\mathrm{Zr}$ octahedra are close to being ideal ( $v$ in the range $0.07-0.87 \%$ ), whereas the larger $\mathrm{Na}$ and $\mathrm{Ca}$ polyhedra may be quite distorted ( $v$ in the range $2.73-11.1 \%$ ).

\section{The M1 site}

The $M 1$ site is octahedrally coordinated to five atoms of oxygen and one mixed fluorine-oxygen site (X8). The five atoms of oxygen constitute the ligands

TABLE 6. BOND LENGTHS $(\AA)$, POLYHEDRON VOLUMES $\left(\AA^{3}\right)$ AND DISTORTION

PARAMETERS* (\%) FOR $M$ POSITIONS IN SAMPLES WBC-13 (GÖTZENITE), LF-A5 (ROSENBUSCHITE) AND 1993.153 (SEIDOZERITE)

\begin{tabular}{|c|c|c|c|c|c|c|c|}
\hline WBC-13 & & $M 1 \mathrm{a}-O 5 \mathrm{~b}$ & $2.088(4)$ & $M 3 \mathrm{~b}-O 3 \mathrm{~b}$ & $2.590(4)$ & $M 2 \mathrm{a}-F 9$ & $2.088(2)$ \\
\hline$M 1-05$ & $2.277(2)$ & $M 1 \mathrm{a}-O 4 \mathrm{~b}$ & $2.109(4)$ & Vol[6] & 17.52 & $M 2 a-F 9$ & $2.088(2)$ \\
\hline$M 1-O 4$ & $2.291(2)$ & $M 1 \mathrm{a}-O 2 \mathrm{a}$ & $2.168(4)$ & $v[6]$ & 4.26 & $M 2 \mathrm{a}-06$ & $2.146(2)$ \\
\hline$M 1-O 3$ & $2.368(2)$ & $M 1 \mathrm{a}-O 3 \mathrm{a}$ & $2.170(3)$ & $M 4 \mathrm{a}-F 9 \mathrm{a}$ & $2.213(3)$ & $M 2 \mathrm{a}-06$ & $2.146(2)$ \\
\hline$M 1-F 8$ & $2.373(2)$ & $M 1 \mathrm{a}-O 3 \mathrm{~b}$ & $2.257(4)$ & $M 4 a-F 9 a$ & $2.213(3)$ & $M 2 \mathrm{a}-X 8$ & $2.312(2)$ \\
\hline$M 1-O 2$ & $2.374(2)$ & Vol[6] & 12.97 & $M 4 \mathrm{a}-07 \mathrm{a}$ & $2.509(4)$ & $M 2 \mathrm{a}-X 8$ & $2.312(2)$ \\
\hline$M 1-O 3$ & $2.379(2)$ & $v[6]$ & 0.79 & $M 4 \mathrm{a}-07 \mathrm{a}$ & $2.509(4)$ & Vol[6] & 13.34 \\
\hline Vol[6] & 16.49 & $\overrightarrow{M 1 b}-05 \mathrm{a}$ & $2.285(4)$ & $M 4 a-O 1 a$ & $2.545(4)$ & $\mathrm{v}[6]$ & 3.89 \\
\hline $0[6]$ & 3.28 & $M 1 \mathrm{~b}-O 4 \mathrm{a}$ & $2.292(4)$ & $M 4 a-O 1 a$ & $2.545(4)$ & $M 2 \mathrm{~b}-O 7$ & $2.343(2)$ \\
\hline$M 2-H 9$ & $\overline{2.34} 1(2)$ & $M 1 \mathrm{~b}-X 8 \mathrm{~b}$ & $2.331(3)$ & $M 4 \mathrm{a}-06 \mathrm{a}$ & $2.639(4)$ & $M 2 \mathrm{~b}-O 7$ & $2.343(2)$ \\
\hline$M 2-F 9$ & $2.347(2)$ & $M 1 \mathrm{~b}-O 2 \mathrm{~b}$ & $2.381(4)$ & $M 4 \mathrm{a}-06 \mathrm{a}$ & $2.639(4)$ & $M 2 \mathrm{~b}-F 9$ & $2.353(2)$ \\
\hline$M 2-O 7$ & $2.374(2)$ & $M 1 \mathrm{~b}-O 3 \mathrm{a}$ & $2.416(4)$ & Vol[ 8$]$ & 24.57 & $M 2 \mathrm{~b}-F 9$ & $2.353(2)$ \\
\hline$M 2-F 8$ & $2.376(2)$ & $M 1 \mathrm{~b}-O 3 \mathrm{~b}$ & $2.450(3)$ & $v[8]$ & 7.69 & $M 2 \mathrm{~b}-X 8$ & $2.582(2)$ \\
\hline$M 2-06$ & $2.384(2)$ & $\operatorname{Vol}[6]$ & 16.91 & $\overrightarrow{M 4 \mathrm{~b}}-F 9 \mathrm{~b}$ & $\overline{2.19} 1(3)$ & $M 2 \mathrm{~b}-X 8$ & $2.582(2)$ \\
\hline$M 2-F 8$ & $2.398(2)$ & $v[6]$ & 2.76 & $M 4 \mathrm{~b}-F 9 \mathrm{~b}$ & $2.191(3)$ & Vol[6] & 17.45 \\
\hline $\mathrm{Vol}[6]$ & 16.36 & $\overline{M 2 \mathrm{a}}-F 9 \mathrm{a}$ & $2.304(4)$ & $M 4 \mathrm{~b}-O 7 \mathrm{~b}$ & $2.584(4)$ & $\underline{v[6]}$ & 7.86 \\
\hline$\underline{v[6]}$ & 7.67 & $M 2 \mathrm{a}-06 \mathrm{a}$ & $2.340(4)$ & $M 4 \mathrm{~b}-O 7 \mathrm{~b}$ & $2.584(4)$ & $M 3-F 9$ & $2.217(2)$ \\
\hline$\overline{M 3}-05$ & $\frac{2.34}{2}(2)$ & $M 2 \mathrm{a}-X 8 \mathrm{~b}$ & $2.352(4)$ & $M 4 \mathrm{~b}-06 \mathrm{~b}$ & $2.620(4)$ & $M 3-O 2$ & $2.361(2)$ \\
\hline$M 3-F 9$ & $2.343(2)$ & $M 2 \mathrm{a}-F 9 \mathrm{~b}$ & $2.362(4)$ & $M 4 \mathrm{~b}-06 \mathrm{~b}$ & $2.620(4)$ & $M 3-O 5$ & $2.423(2)$ \\
\hline$M 3-O 4$ & $2.357(2)$ & $M 2 \mathrm{a}-O 7 \mathrm{~b}$ & $2.409(4)$ & $M 4 \mathrm{~b}-O \mathrm{lb}$ & $2.676(4)$ & $M 3-O 4$ & $2.484(2)$ \\
\hline$M 3-O 2$ & $2.359(2)$ & $M 2 \mathrm{a}-X 8 \mathrm{a}$ & $2.483(4)$ & $M 4 \mathrm{~b}-O 1 \mathrm{~b}$ & $2.676(4)$ & $M 3-O 2$ & $2.548(2)$ \\
\hline$M 3-O 2$ & $2.533(2)$ & Vol[6] & 16.81 & Vol[8] & 25.96 & $M 3-O 3$ & $2.661(2)$ \\
\hline$M 3-O 3$ & $2.534(2)$ & $v[6]$ & 5.85 & $v[8]$ & 7.14 & $M 3-O 1$ & $2.848(2)$ \\
\hline$M 3-O 1$ & $2.986(2)$ & $M 2 \mathrm{~b}-F 9 \mathrm{a}$ & $\overline{2.30} 6(4)$ & $\overrightarrow{M 5 \mathrm{a}}-07 \mathrm{a}$ & $\overline{2.03} 8(3)$ & $M 3-O 1$ & $2.882(2)$ \\
\hline Vol[6] & 17.62 & $M 2 \mathrm{~b}-07 \mathrm{a}$ & $2.330(4)$ & $M 5 \mathrm{a}-07 \mathrm{a}$ & $2.038(3)$ & Vol[6] & 17.70 \\
\hline$v[6]$ & 5.26 & $M 2 \mathrm{~b}-F 9 \mathrm{~b}$ & $2.344(4)$ & $M 5 \mathrm{a}-06 \mathrm{a}$ & $2.044(3)$ & $v[6]$ & 9.31 \\
\hline Vol[7] & 21.43 & $M 2 \mathrm{~b}-06 \mathrm{~b}$ & $2.359(4)$ & $M 5 \mathrm{a}-06 \mathrm{a}$ & $2.044(3)$ & Vol[8] & 26.20 \\
\hline$v[7]$ & 6.76 & $M 2 \mathrm{~b}-X 8 \mathrm{~b}$ & $2.365(4)$ & $M 5 \mathrm{a}-X 8 \mathrm{a}$ & $2.053(3)$ & v[ [8] & 9.88 \\
\hline$\frac{1}{M 4-F 9}$ & $2.225(2)$ & $M 2 \mathrm{~b}-X 8 \mathrm{a}$ & $2.488(3)$ & $M 5 \mathrm{a}-X 8 \mathrm{a}$ & $2.053(3)$ & $M 4-19$ & $2.204(2)$ \\
\hline$M 4-F 9$ & $2.225(2)$ & $\mathrm{Vol}[6]$ & 16.54 & Vol[6] & 11.38 & $M 4-F 9$ & $2.204(2)$ \\
\hline$M 4-O 1$ & $2.379(2)$ & $v[6]$ & 5.98 & $v[6]$ & 0.19 & M4-O7 & $2.521(2)$ \\
\hline$M 4-O 1$ & $2.379(2)$ & $M 3 \mathrm{a}-F 9 \mathrm{a}$ & $2.268(3)$ & $\overrightarrow{M 5 b}-X 8 \mathrm{~b}$ & $1.992(3)$ & $M 4-O 7$ & $2.521(2)$ \\
\hline$M 4-07$ & $2.547(2)$ & $M 3 \mathrm{a}-O 2 \mathrm{~b}$ & $2.352(4)$ & $M 5 \mathrm{~b}-X 8 \mathrm{~b}$ & $1.992(3)$ & $M 4-O 6$ & $2.555(2)$ \\
\hline$M 4-O 7$ & $2.547(2)$ & $M 3 \mathrm{a}-O 5 \mathrm{~b}$ & $2.433(4)$ & $M 5 \mathrm{~b}-06 \mathrm{~b}$ & $2.004(4)$ & M4-06 & $2.555(2)$ \\
\hline$M 4-06$ & $2.728(2)$ & $M 3 \mathrm{a}-O 4 \mathrm{~b}$ & $2.505(4)$ & $M 5 \mathrm{~b}-O 6 \mathrm{~b}$ & $2.004(4)$ & $M 4-O 1$ & $2.693(2)$ \\
\hline M4-O6 & $2.728(2)$ & $M 3 \mathrm{a}-O 2 \mathrm{a}$ & $2.603(4)$ & $M 5 \mathrm{~b}-O 7 \mathrm{~b}$ & $2.008(3)$ & $M 4-O 1$ & $2.693(2)$ \\
\hline Vol[8] & 24.79 & $M 3 \mathrm{a}-O 3 \mathrm{a}$ & $2.658(4)$ & $M 5 \mathrm{~b}-O 7 \mathrm{~b}$ & $2.008(3)$ & Vol[8] & 25.03 \\
\hline$v[8]$ & 6.12 & $M 3 a-O 1$ a & $2.712(4)$ & Vol[6] & 10.68 & $v[8]$ & 7.88 \\
\hline M5-O7 & $1.957(2)$ & $M 3 \mathrm{a}-O 1 \mathrm{~b}$ & $2.827(5)$ & $v[6]$ & 0.11 & $M 5-07$ & $1.923(2)$ \\
\hline$M 5-07$ & $1.957(2)$ & Vollo] & 18.47 & $\overline{1993} .153$ & & $M 5-07$ & $1.923(2)$ \\
\hline$M 5-06$ & $1.964(2)$ & $v[6]$ & 7.70 & $M 1-X 8$ & $1.988(2)$ & $M 5-X 8$ & $1.979(2)$ \\
\hline M5-O6 & $1.964(2)$ & Vol[8] & 26.08 & $M 1-O 4$ & $1999(2)$ & $M 5-X 8$ & $1.979(2)$ \\
\hline$M 5-F 8$ & $1.995(2)$ & $\mathrm{v}[8]$ & 9.37 & $M 1-O 5$ & $2.007(2)$ & $M 5-06$ & $2.011(1)$ \\
\hline$M 5-F 8$ & $1.995(2)$ & $\overline{M 3 b}-F 9 b$ & $2.277(3)$ & $M 1-O 2$ & $2.053(2)$ & $M 5-06$ & $2.011(1)$ \\
\hline Vol[6] & 10.2 & $M 3 \mathrm{~b}-O 5 \mathrm{a}$ & $2.318(4)$ & $M 1-O 3$ & $2.178(1)$ & Vol[6] & 10.18 \\
\hline$v[6]$ & 0.25 & $M 3 \mathrm{~b}-O 4 \mathrm{a}$ & $2.335(4)$ & $M 1-O 3$ & $2.257(2)$ & $v[6]$ & 0.37 \\
\hline LF-A5 & & $M 3 \mathrm{~b}-O 2 \mathrm{a}$ & $2.389(4)$ & Vol[6] & 11.80 & & \\
\hline$M 1$ a- $X 8 \mathrm{a}$ & $2.071(3)$ & $M 3 \mathrm{~b}-O 2 \mathrm{~b}$ & $2.486(4)$ & $v[6]$ & 0.67 & & \\
\hline
\end{tabular}

* Distortion parameter (Makovicky \& Balić-Žunić 1998): $v=\left(V_{i}-V_{t}\right) / V_{i}^{*} 100, V_{i}=$ ideal volume of polyhedron, $\mathrm{V}_{\mathrm{r}}=$ real volume of polyhedron. The ideal polyhedra are octahedron for $\mathrm{CN}=[6]$, pentagonal bipyramid for $\mathrm{CN}$ $=[7]$ and square antiprism with maximum volume for $\mathrm{CN}=[8]$. 
common to the octahedra sharing edges with $M 1$, and link furthermore to five tetrahedra. One $M 1$ and three $M 3$ octahedra are joined to the edges of the same $M 1$ octahedron, whereas the mixed $X 8$ site is shared with three octahedra in the $O$ layer (Fig. 5).

$\mathrm{Ca}, \mathrm{Zr}, \mathrm{Mn}$ and $\mathrm{Y}$ are the main elements occupying the $M 1$ sites, and the volumes of these octahedra are the most variable in the structures (Table 6).

The smallest $M 1$ octahedron is to be found in seidozerite. It hosts primarily $\mathrm{Zr}(70 \%)$ and $\mathrm{Ti}(20 \%)$ and has a volume of $11.8 \AA^{3}$. The degree of distortion of the octahedron is $0.67 \%$, and thus close to ideal. However, the individual $\mathrm{Zr}-\mathrm{O}$ bonds vary within the octahedron, the bonds to the two ligands (O3) common to two $M 1$ octahedra being longer (Fig. 6). Seidozerite is one of the very rare minerals in which two $\mathrm{Zr}$ octahedra share an edge, and the longer bonds to $O 3$ compensate for the direct repulsion between the two $\mathrm{Zr}$ cations and for the overbonding of $\mathrm{O3}$.

In the variants of the rosenbuschite structure, the two distinct $M 1$ octahedra have significantly different vol- umes. The Zr-dominant $M 1$ a octahedron has a volume of $\sim 13 \AA^{3}$, whereas the volume of the Ca-dominant $M 1 \mathrm{~b}$ octahedron is $\sim 17 \AA^{3}$. The $M 1 \mathrm{~b}$ octahedron in kochite (WBC-12) is smaller (15.7 $\AA^{3}$, not listed), in accordance with $\mathrm{Mn}$ as the dominant element at this site. The $\mathrm{Zr}$ dominated $M 1$ a octahedra are slightly larger than the $M 1$ of seidozerite, owing to minor incorporation of $\mathrm{Ca}$.

With respect of volume (16.49 $\AA^{3}$ ) and distortion, the Ca-dominant $M 1$ octahedron in götzenite is almost identical to the $M 1 \mathrm{~b}$ octahedron in rosenbuschite. The $M 1$ octahedron in sample LF-A2 differs from the one in WBC-13 only by being slightly smaller $\left(15.95 \AA^{3}\right.$, not listed), owing to the incorporation of significant amounts of $\mathrm{Y}$.

\section{The M5 site}

The $M 5$ octahedron is part of the layer of octahedra, and shares the edges of four $M 2$ octahedra and two $M 4$ polyhedra. The four corners shared with the $M 4$ polyhedra also link to four Si tetrahedra (Fig. 5). The two

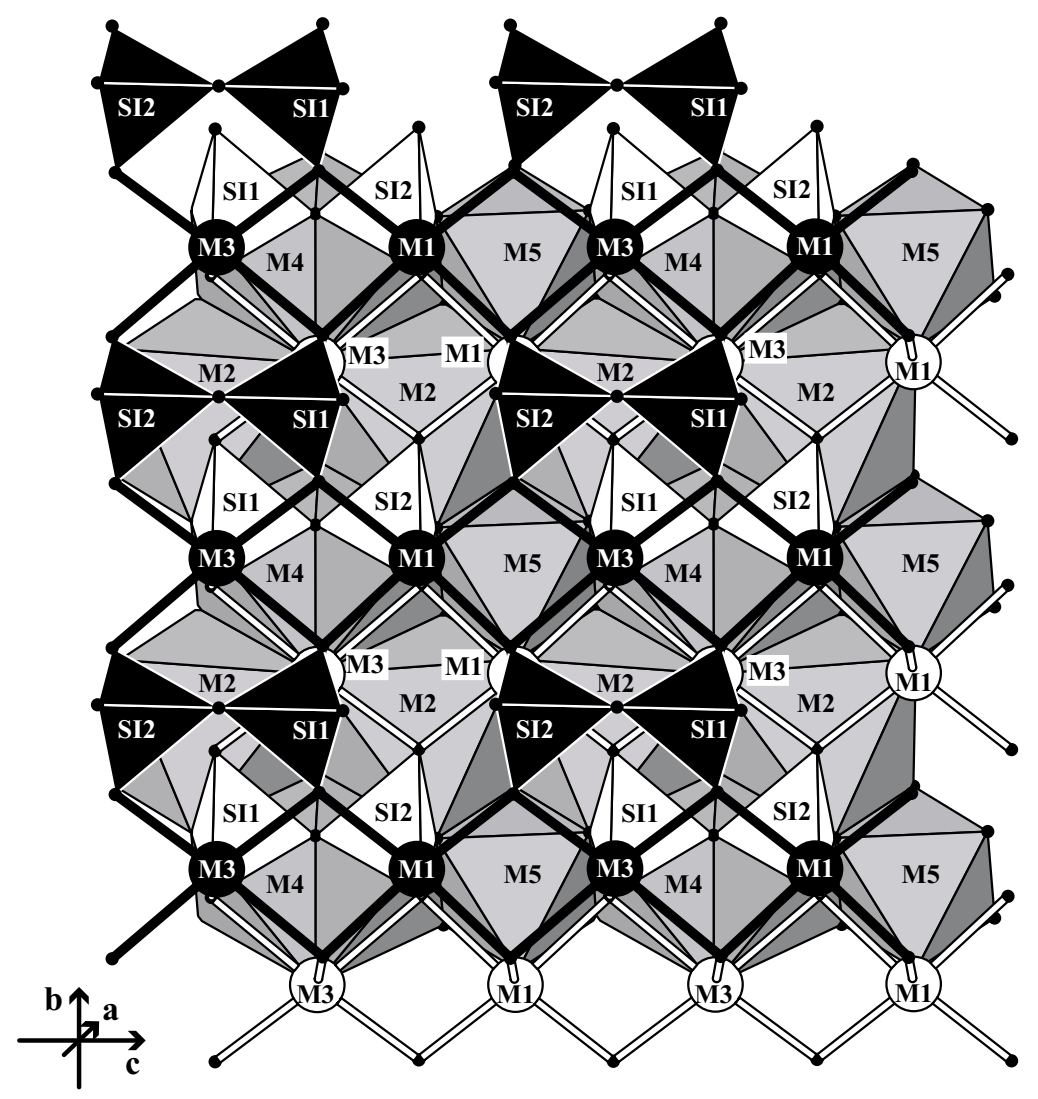

FIG. 5. The $O-H-H$ layer of the götzenite structure projected onto (100). The $O$ layers are indicated by grey polyhedra, whereas the tetrahedra, atoms and bonds shown in black and white indicate, respectively, the upper and lower $H$ layers. 
remaining ligands are the mixed $X 8$ sites, which are also shared by $M 1$ octahedra. Ti is by far the most common occupant of the site in rosenbuschite, though significant amounts of $\mathrm{Zr}$ are present. The volumes of the octahedra vary little, from 10.18 to $11.38 \AA^{3}$, the larger octahedra being occupied mainly by $\mathrm{Zr}$.

The average bond-lengths of the Ti-dominated octahedra vary between 1.970 to $2.001 \AA$, which are longer than the ideal $\mathrm{Ti}^{[6]}{ }^{[6} \mathrm{O}^{[4]}$ distance of $1.965 \AA$. Minor replacement of $\mathrm{Ti}$ by $\mathrm{Fe}, \mathrm{Nb}$ and $\mathrm{Zr}$ partly explains this, but still a systematically deviation between the BVS and VS of these sites is observed (Table 4). This deviation is associated with high displacement-factors of $\mathrm{Ti}$, which is elongate along the $X 8-X 8$ diagonal of the coordination octahedra, as shown in Figure 7a. If this phenomenon is interpreted as a static disorder, Ti would be displaced from the center of symmetry toward one of the corners, which changes the individual bond-lengths to an asymmetrical coordination. Figure $7 \mathrm{~b}$ shows the estimated effect of such a displacement on the deviation of BVS and VS, and of the ideal and average bondlengths. Note that the BVS is more sensitive to the displacement, whereas the average bond-length changes only slightly. The Zr-dominated M5 site has significantly lower displacement-factors and better VS-BVS balance.

\section{The $\mathrm{Si}_{2} \mathrm{O}_{7}$ group}

Table 7 lists some geometrical features of the $\mathrm{Si}_{2} \mathrm{O}_{7}$ groups. The average $\mathrm{Si}-\mathrm{O}$ bond length for the tetrahe-

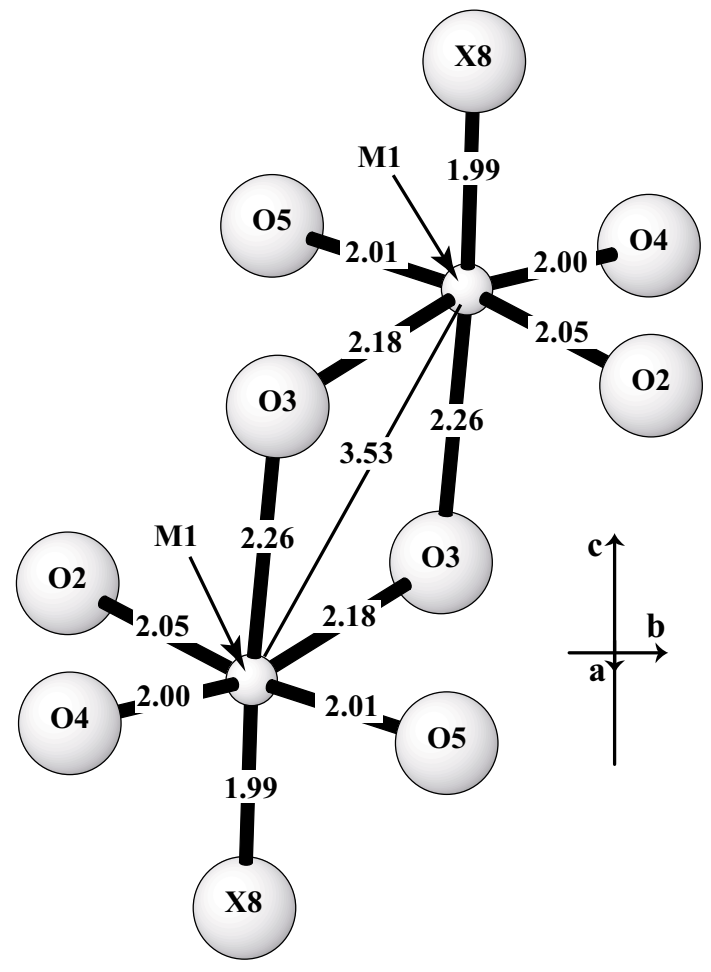

FIG. 6. The two edge-sharing Zr-bearing octahedra in seidozerite seen perpendicular to (001). Interatomic distances are given in Ångströms.

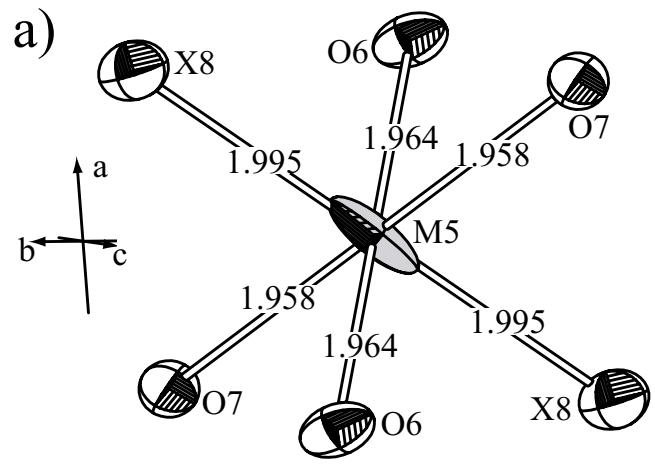

b)

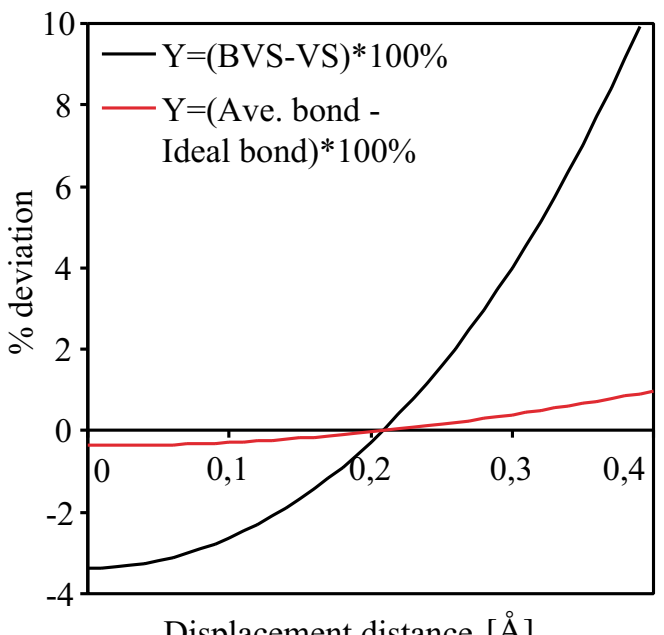

FIG. 7. a) Inclined view of the $M 5$ polyhedron showing the central Ti cation and the coordinating anions as ellipsoids to indicate their thermal vibrations. Bond lengths are given in A. Sample WBC-13 (götzenite) is shown. b) Graph showing the calculated effect of a displacement of the central Ti upon its bond-valence summation (BVS) and average bond-length. The basis for the calculation is an ideal octahedron with a bond length of $1.985 \AA$ to the non-displaced Ti and a displacement direction toward $\mathrm{X} 8$. In this hypothetical case, Ti is likely to be displaced $\sim 0.2 \AA$ off the center. 

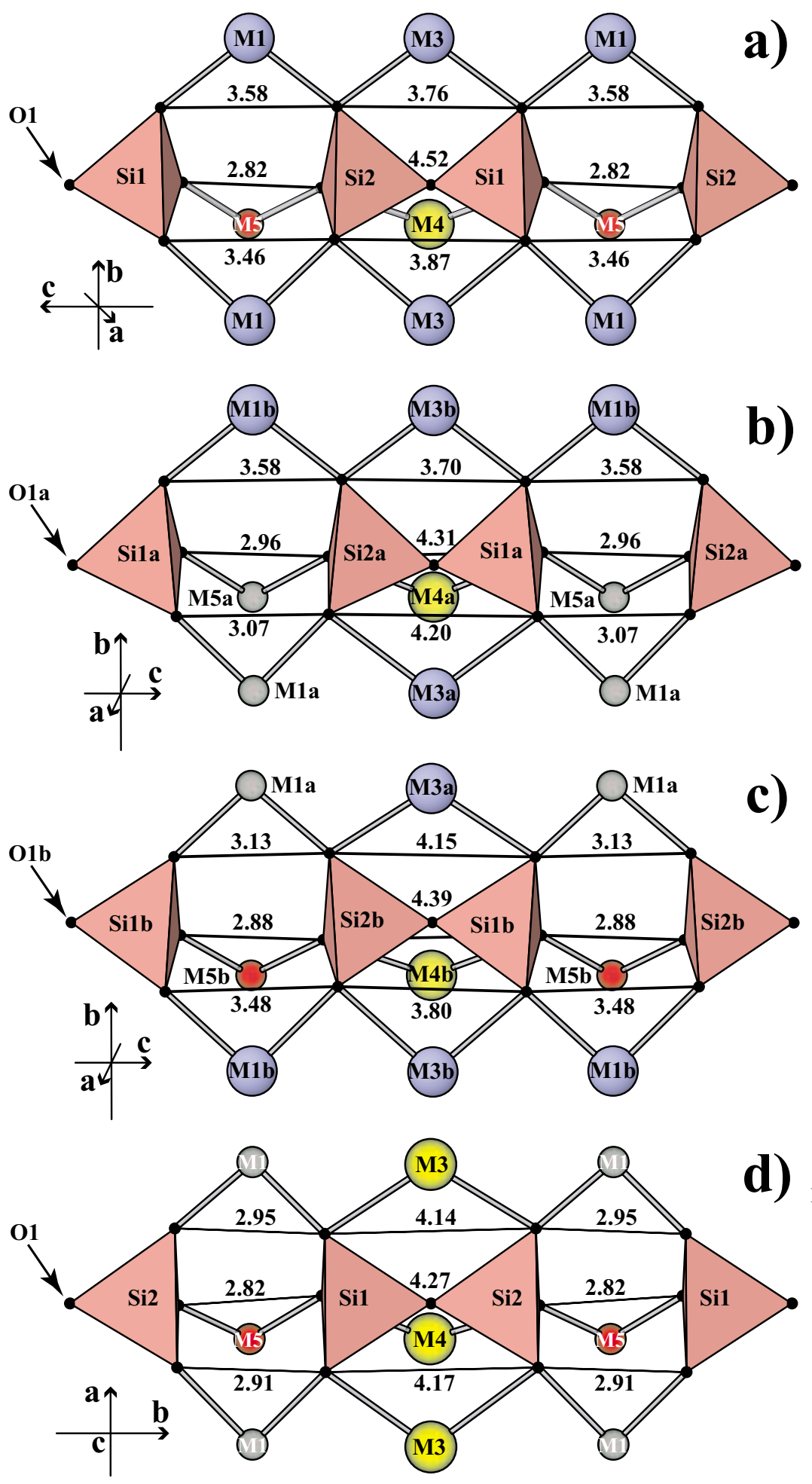

FIG. 8. The rows of disilicate groups along with their surrounding cations, showing the degree of distortion of the disilicate groups in relation to the size of the $M 1$ and $M 5$ cations. The letters represents a) WBC- 13 [götzenite], b, c) LF-A5 [rosenbuschite], and d) 1993.158 [seidozerite]. The atoms are represented by blue $(\mathrm{Ca})$, yellow $(\mathrm{Na})$, grey $(\mathrm{Zr})$ and red (Ti) spheres. 
dra are within the ranges of 1.6162 to $1.6265 \AA$. The bonds to the bridging oxygen atoms $(O 1)$ are generally significantly longer than the remaining $\mathrm{Si}-\mathrm{O}$ bonds, but in the seidozerite structure, no clear distinction among the bond lengths is apparent.

The BVS calculations invariably show evidence of overbonding of $O 1$ by approximately 0.2 valence units (Table 5). A similar overbonding of the bridging oxygen has also been observed in members of the låvenitewöhlerite group (Mellini 1981, Perchiazzi et al. 2000). As Mellini pointed out, these systematic deviations may be due to the correlation between bond valence and bond length, which does not take into account other parameters like bond angles and mutual screening among anions.

The $\mathrm{Si}-\mathrm{O}-\mathrm{Si}$ angle and the angles between the two basal planes of the $\mathrm{Si}_{2} \mathrm{O}_{7}$ dimers (Table 7) are closely related to the size of the $M 1$ and $M 5$ octahedra (Fig. 8). Two $M 1$ and one $M 5$ octahedra link the basal corners of adjacent disilicate groups, and any difference in size between the three octahedra sets the corners in one basal plane at different levels of $c$, resulting in an inclination between the two basal faces at the ends of the disilicate group. In seidozerite, the presence of three small $\mathrm{Zr}$ - and Ti-bearing octahedra result in a small inclination of $2.82^{\circ}$, whereas rosenbuschite and götzenite have, respectively, one and two large $\mathrm{Ca}$ octahedra in $M 1$, rePROPERTIES OF SiO TETRAHEDRA AND $\mathrm{Si}_{2} \mathrm{O}_{2}$ GROUPS IN MINERALS OF THE ROSENBUSCHITE GROUP

Sample no. WBC-13 WBC-12 WBC-12 LF-A2 LF-A5 LF-A5 1993.158

\begin{tabular}{lllllll}
\hline Si site & Sil & Sila & Silb & Sil & Sila & Silb
\end{tabular}

01 1.651(2) $1.641(3) 1.643(3) 1.641(2) 1.644(4) 1.642(4) \quad 1.626(1)$

$\begin{array}{llllllll}01 & 1.651(2) & 1.641(3) & 1.643(3) & 1.641(2) & 1.644(4) & 1.642(4) & 1.626(1)\end{array}$ $\begin{array}{llllllll}O 2 & 1.611(2) & 1.625(2) & 1.605(3) & 1.618(3) & 1.624(3) & 1.609(4) & 1.612(2)\end{array}$

$\begin{array}{lllllllll}04 & 1.605(2) & 1.594(3) & 1.618(2) & 1.609(3) & 1.604(4) & 1627(4) & 1.622(1)\end{array}$

$\begin{array}{lllllllll}6 & 1.626(2) & 1.621(2) & 1.618(2) & 1.629(2) & 1.614(3) & 1.628(4) & 1.626(1)\end{array}$

$\begin{array}{llllllll}\text { Ave.(4) } & 1.623 & 1.620 & 1.621 & 1.624 & 1.621 & 1.627 & 1.622\end{array}$

$\begin{array}{llllllll}\text { Volume } & 2.171 & 2.164 & 2.167 & 2.178 & 2.166 & 2.189 & 2.177\end{array}$

$\begin{array}{llllllll}\text { 001] rot. } & 5.56 & 3.13 & 5.71 & 4.78 & 2.61 & 6.21 & 2.76\end{array}$

\begin{tabular}{llllllll}
\hline Si site & $S i 2$ & $S i 2 \mathrm{a}$ & $S i 2 \mathrm{~b}$ & $S i 2$ & $S i 2 \mathrm{a}$ & $S i 2 \mathrm{~b}$ & $S i 2$
\end{tabular}

\begin{tabular}{|c|c|c|c|c|c|c|c|}
\hline $\begin{array}{l}O 1 \\
O 3 \\
\text { O5 } \\
\text { O7 } \\
\text { Ave.(4) } \\
\text { Volume } \\
\text { [001] rot.* }\end{array}$ & $\begin{array}{l}1.652(2) \\
1.603(2) \\
1.600(2) \\
1.626(2) \\
1.620 \\
2.156 \\
9.20\end{array}$ & $\begin{array}{l}1.627(3) \\
1.614(2) \\
1.590(3) \\
1.620(3) \\
1.613 \\
2.133 \\
7.31\end{array}$ & $\left\{\begin{array}{l}1.627(2) \\
1.614(2) \\
1.612(2) \\
1.618(3) \\
1.618 \\
2.156 \\
10.78\end{array}\right.$ & $\begin{array}{l}1.644(2) \\
1.611(3) \\
1.600(3) \\
1.618(3) \\
1.618 \\
2.153 \\
8.51\end{array}$ & 2) $\begin{array}{l}1.636(4) \\
1.627(3) \\
1.583(4) \\
1.618(3) \\
1.616 \\
2.142 \\
6.43\end{array}$ & $\begin{array}{l}\text { 4) } 1.635(4) \\
\text { 3) } 1.628(3) \\
\text { 4) } 1.625(4) \\
\text { 3) } 1.611(3) \\
1.625 \\
2.185 \\
11.27\end{array}$ & $\left\{\begin{array}{l}1.622(1) \\
1.635(2) \\
1.605(1) \\
1.622(1) \\
1.621 \\
2.174 \\
9.69\end{array}\right.$ \\
\hline angle** & 62.2 & 167.7 & 167.9 & 164.6 & 165.9 & 167.4 & 177.2 \\
\hline
\end{tabular}

* Rotation of tetrahedra around [001] $\left({ }^{\circ}\right)$, measured as the angle between $(100)$ and the $O 2-O 4$ edge to $S i 1$ and $O 3-O 5$ to $S i 2 .{ }^{* *}$ Angle between basal faces $\left({ }^{\circ}\right)$ of the diorthosilicate groups. All volumes and angles are calculated using the program IVTON (Balić-Žuić \&Vickovic 1986). Interconnected tetrahedra are listed in same column. Sample TYROS is not listed.

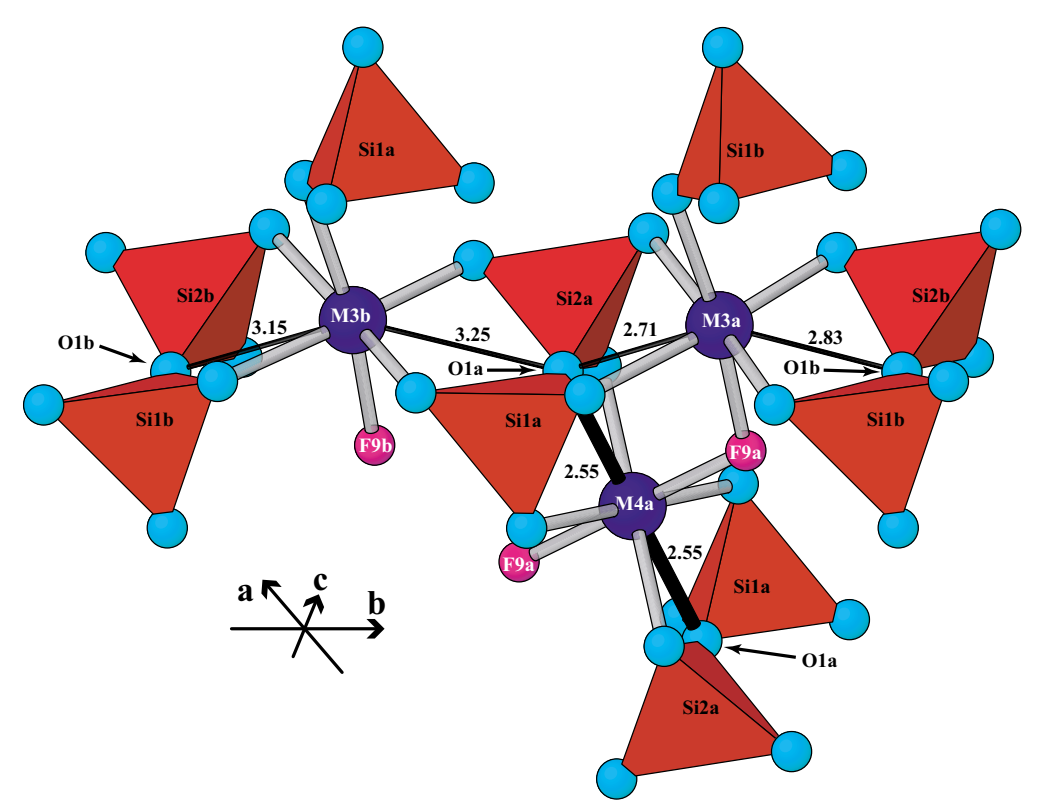

FIG. 9. A ball-and-stick model of the coordination polyhedra to the $M 3 \mathrm{a}, M 3 \mathrm{~b}$ and $M 4 \mathrm{a}$ positions in rosenbuschite (sample LF-A5), in an oblique view. The cation-O1 bonds are indicated in black, and their lengths are given in $\AA$. Light blue and purple spheres represent $\mathrm{O}$ and $\mathrm{F}$, respectively. 
sulting in a larger inclination $\left(12.6^{\circ}\right.$ to $\left.17.77^{\circ}\right)$. The difference between the $\mathrm{Si}-\mathrm{O}-\mathrm{Si}$ angle and the basal angle is due to distortion within the individual tetrahedra.

\section{The M3 and M4 sites}

Figure 8 also shows that the disilicate groups are riding on the edges of the $M 3$ and $M 4$ polyhedra. Each (M3, M4) polyhedron is attached to two disilicate groups. The distances between the pairs of vertices of the $\mathrm{Si}_{2} \mathrm{O}_{7}$ group and the $c$ dimension of these polyhedra are thus coincident (Fig. 8). For the ideal Ca-bearing octahedron and $\mathrm{Si}_{2} \mathrm{O}_{7}$ group, this dimension would deviate by $\sim 1 \AA$ (3.34 and $4.32 \AA$, respectively). This misfit is compensated by bending the $\mathrm{Si}_{2} \mathrm{O}_{7}$ groups and by a high degree of distortion of the $(M 3, M 4)$ polyhedra. The polyhedra are stretched along $c$, and in order to maintain realistic bond-lengths within the polyhedra, they are flattened perpendicular to the ribbon or layer. The edges shared with $M 1$ or $M 5$ become shorter in this way, and assume dimensions equal to that of a $\mathrm{Zr}$ or $\mathrm{Ti}$ octahedron. Owing to this stretch, $v$ is relative large for these octahedra, and varies between 4.26 and $11.1 \%$.

The bridging oxygen $(O 1)$ in the disilicate group is located centrally between two $M 3$ and one $M 4$ positions. The distance to these three cations varies between 2.379 to $3.2 \AA$. This variation is geometrically correlated with the $\mathrm{Si}-\mathrm{O}-\mathrm{Si}$ angle, and its orientation. Since the obtuse part of the angle points in the direction of the $O$ layer, the $O 1-M 4$ distance is the shorter of the three (2.379 to $2.693 \AA$ ). $M 4$ is therefore considered to be in an eightfold coordination, which can best be described as a distorted hexagonal bipyramid. The distance to the two M3 positions is in the range $2.7-3.2 \AA$. In the structure of rosenbuschite variants (Fig. 9), the $O 1-M 3$ a distance, $\sim 2.8 \AA$, is significantly shorter than $O 1-M 3 \mathrm{~b}, \sim 3.2 \AA$. Correlated with this difference are also the distortion parameters for their octahedral coordination, $v$ being higher for the $M 3 \mathrm{a}$ octahedra and lower for the $M 3 \mathrm{~b}$ octahedra. The occupancies of the two $M 3$ positions also differ in that $25 \% \mathrm{Na}$ enters $M 3 \mathrm{a}$, whereas $M 3 \mathrm{~b}$ is fully occupied by $\mathrm{Ca}$. The $M 3$ a polyhedron shares edges with two high-charge Zr-bearing octahedra, whereas $M 3 \mathrm{~b}$ is only linked to one, and a lower valence on the $M 3$ a site may therefore be preferred.

\section{The M2 sites}

The $M 2$ positions are octahedrally coordinated by two $F 9$, two $X 8$ and two atoms of oxygen (O6 and $O 7$ ), the oxygen atoms being shared with two $\mathrm{SiO}_{4}$ tetrahedra. Through the two edges composed of the $F 9$ and $X 8$ ligands, $M 2$ octahedra link into columns parallel to the $c$ axis. Besides the edges shared with the two adjacent $M 2$ octahedra, each $M 2$ octahedron also shares edges with two relatively small $M 5$ octahedra on one side and two larger M4 polyhedra on the other side (Fig. 5).
In the triclinic structures, the geometrical properties of the $M 2$ octahedra are fairly constant, their volumes ranging between 16.27 and $16.81 \AA^{3}$, and the degree of distortion, between 5.9 and $7.7 \%$. These octahedra plus the $M 2 \mathrm{~b}$ octahedron in seidozerite all accommodate $\mathrm{Na}$ and $\mathrm{Ca}$, whereas the $M 2 \mathrm{a}$ octahedron of seidozerite is occupied by $\mathrm{Mn}$ and $\mathrm{Mg}$, and thus is significantly smaller $\left(13.34 \AA^{3}\right)$. As mentioned above, seidozerite deviates from the other members of the group by having only relatively small $M 1$ octahedra, which results in a $b$ dimension shorter than that in the triclinic structuretypes (7.0752 ̊ versus 7.202-7.3307 $\AA$ ). This difference is in accordance with the incorporation of a small Mn octahedron into the $M 2$ column.

\section{Discussion on the Solid Solution Involving the Members of the Rosenbuschite Group}

Cannillo et al. (1972) introduced the idea of an isomorphous series between götzenite and seidozerite. Such a series would, however, imply fully replaceable $\mathrm{Ca}$ and $\mathrm{Zr}$. Coupled with $\mathrm{Ca}-\mathrm{Zr}$ substitution, the charge balance would be maintained by also substituting $\mathrm{Ca}$ by $\mathrm{Na}$, and $\mathrm{F}$ by $\mathrm{O}$. Two plots of chemical data (Fig. 10) show the degree of solid solution between these two end-members. A series of intermediate compositions exists between götzenite and rosenbuschite, whereas a compositional gap exists between rosenbuschite and seidozerite. In structures with mixed $(\mathrm{Ca}, \mathrm{Zr})$ occupancy of the $M 1$ positions, half of the $M 1$ positions thus are invariably occupied by Ca. Thus, two Zr octahedra need not share edges, as in seidozerite. The incorporation of a smaller $\mathrm{Zr}$ octahedron in $M 1$ in the structure of rosenbuschite is compensated by adjusting the shape of surrounding polyhedra (especially the $M 3$ positions) allowing, however, the same type of cations $(\mathrm{Na}, \mathrm{Ca})$ in these polyhedra. The two edge-sharing $\mathrm{Zr}$-bearing octahedra in seidozerite lead to a pronounced contraction of the structure, which is furthermore enhanced by the presence of a Mn octahedron in one of the $M 2$ sites. This configuration leads to the monoclinic mode of stacking of the $\mathrm{HOH}$ layers in seidozerite, whereas the triclinic mode of stacking characterizes the members with $M 1$ fully or partially occupied by $\mathrm{Ca}$. These geometrical differences result in a dimensional misfit between the rosenbuschite and seidozerite structures, which cannot be compensated, and the two configurational polytypes may not combine, resulting in the compositional gap observed in Figure 10.

\section{The Role of ZirCONIUM}

A plot of $\mathrm{Zr}$ versus $\mathrm{Ti}+\mathrm{Nb}$ is shown in Figure 11 . Except for the composition of seidozerite, all points fall within one of two trends. For $\mathrm{Zr}<1.5$ apfu, the sum Ti $+\mathrm{Nb}$ has a fairly constant value, just below 2 apfu, whereas a negative 1:1 correlation is observed at higher 
values of $\mathrm{Zr}$. In the compositions poor in $\mathrm{Zr}$, the $M 5$ sites are occupied by $\mathrm{Ti}$ and $\mathrm{Nb}$. With increasing $\mathrm{Zr}$, the sum $\mathrm{Ti}+\mathrm{Nb}$ remains unaffected because $\mathrm{Zr}$ enters the structure at the expense of $\mathrm{Ca}$ at the $M 1$ site. At $\mathrm{Zr}>1.5$ $a p f u$, the $M 1$ a site is saturated with respect of $\mathrm{Zr}$, and this element now enters the structure at the expense of Ti. Notice that Ti does not drop below 1 apfu in the specimens examined, which indicates that one of the two M5 positions (M5b) is occupied by Ti. The sum of $\mathrm{Ti}$, $\mathrm{Zr}$ and $\mathrm{Nb}$ never exceeds 4 , which is in accordance with the total number of $M 1 \mathrm{a}$ and $M 5$ sites in the unit cell of rosenbuschite.

The data plotted suggest two compositional series involving three end-members, one series between götzenite and kochite, which differ in $\mathrm{Ca} / \mathrm{Zr}$ in the $M 1 \mathrm{a}$
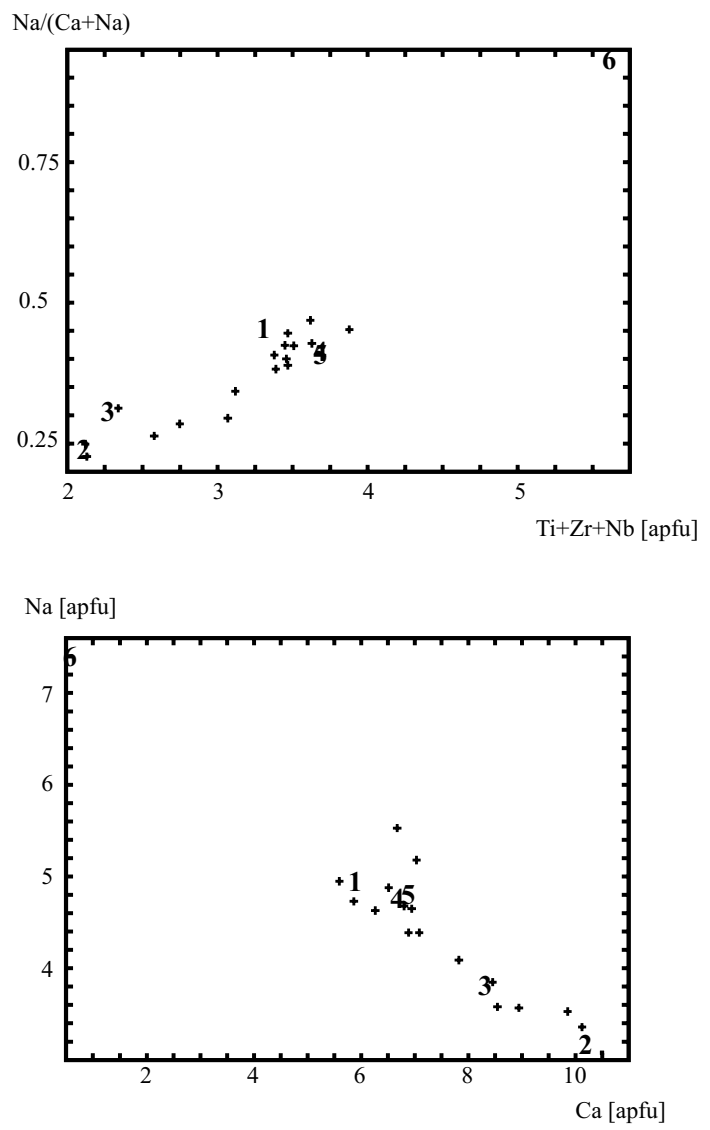

FIg. 10. a) Concentrations of $\mathrm{Ti}+\mathrm{Zr}+\mathrm{Nb}$ versus $\mathrm{Na} /(\mathrm{Ca}+$ $\mathrm{Na}$ ), and b) concentration of $\mathrm{Ca}$ versus that of $\mathrm{Na}$, showing the compositional range of the specimens investigated. The numbers refer to the specimens investigated structurally: 1 : WBC-12 (kochite), 2: WBC-13 (götzenite), 3: LF-A2 (hainite), 4: LF-A5 (rosenbuschite), 5: TYROS (rosenbuschite), and 6: 1993.158 (seidozerite). sites, and another series between kochite and rosenbuschite, with variable $\mathrm{Ti} / \mathrm{Zr}$ in the $M 5 \mathrm{a}$ site. Consequently, Figure 11 indicates that $\mathrm{Zr}$ enters the $M 5 \mathrm{a}$ site only in samples with a high $\mathrm{Zr}$ content at the $M 1$ a site. The relationship may, however, not be universal, as the chemical compositions of Ca-rich samples of götzenite indicate significant amounts of $\mathrm{Zr}$ in the M5 site (up to $25 \%$ ) in the work of Sharygin et al. (1996).

The degree of order of $\mathrm{Zr}$ and $\mathrm{Ti}$ at the $M 5$ sites in rosenbuschite can be correlated with the distribution of $\mathrm{Zr}$ and $\mathrm{Ca}$ at the $M 1$ sites. In Figure 12, the two M5 octahedra are shown in relation with the $M 1$ octahedra linked to their corners. The $M 5$ a octahedron is linked to two $M 1$ a octahedra through the $X 8 \mathrm{a}$ anion, and the $M 5 \mathrm{~b}$ octahedron is linked to two $M 1 \mathrm{~b}$ octahedra through $X 8 \mathrm{~b}$. As described above, the Zr-dominant M1a octahedron is considerably smaller than the Ca-dominant $M 1 \mathrm{~b}$ octahedron. The contraction of the $M 1$ a octahedra has an expanding effect on the M5a octahedron, whereas the large $M 1 \mathrm{~b}$ octahedra are combined with a slightly smaller $M 5 b$ octahedron. As the ionic radius of $\mathrm{Zr}$ is slightly larger than $\mathrm{Ti}$, the two cations are ordered at the two distinct $M 5$ sites.

In addition to this finding, the oxygen:fluorine ratio in the $X 8 \mathrm{a}$ and $X 8 \mathrm{~b}$ sites varies. $X 8 \mathrm{a}$, which is bonded to $\mathrm{Zr}$ at the $M 1 \mathrm{a}$ site, is dominated by oxygen, and the $X 8 \mathrm{~b}$, bonded to $\mathrm{Ca}$ at the $M 1 \mathrm{~b}$ site, is dominated by fluorine (Table 5). Thus the M5a position is primarily bonded to two atoms of oxygen in the $X 8$ positions, whereas $M 5 \mathrm{~b}$ primarily is bonded to fluorine, which differentiates the crystal-chemical character of the M5 positions even further.

\section{The Two Configurational Polytypes}

The main crystal-chemical features of the rosenbuschite group of minerals have now been outlined. The existence of the two configurational polytypes remains to be explained. The two modes of stacking are each characterized by certain crystal-chemical properties. Especially important in this respect is the difference in size of $M 2 \mathrm{a}$ and $M 2 \mathrm{~b}$ in seidozerite versus the fairly constant sizes of the $M 2$ octahedra in the triclinic structures. A chain of arguments can be made by combining the sizes of the $M 2$ octahedra with the rotations of the Si tetrahedra and the mode of stacking.

\section{The monoclinic structure}

The first step is to understand the relationship between sizes of the two $M 2$ octahedra and the degree of rotation around [010] of the two tetrahedra attached to them. In seidozerite, the rotation of the Sil tetrahedron is $2.76^{\circ}$, and the $\mathrm{Si} 2$ tetrahedron is rotated $9.69^{\circ}$ (Table 7). As shown in Figure 13, the relatively small M2a octahedron is linked to two Sil tetrahedra with a small degree of rotation, whereas the larger $M 2 \mathrm{~b}$ octahedron is linked to two Si2 tetrahedra with a more pro- 


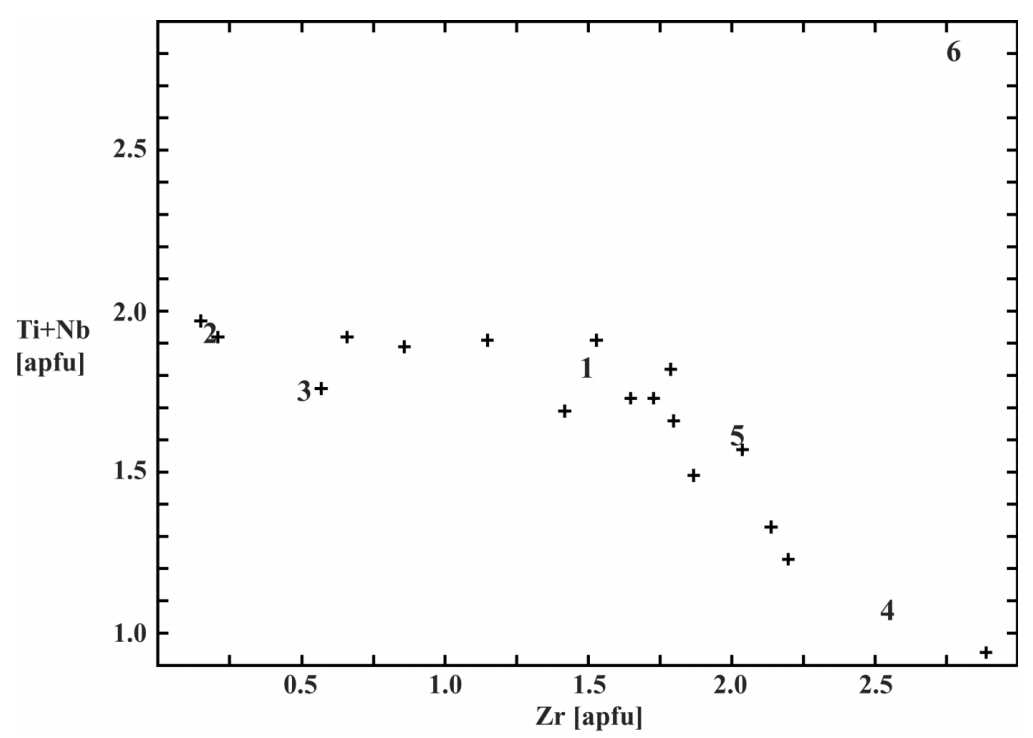

FIG. 11. Concentration of $\mathrm{Zr}$ versus that of $\mathrm{Ti}+\mathrm{Nb}$. Reference numbers as in Figure 10 .

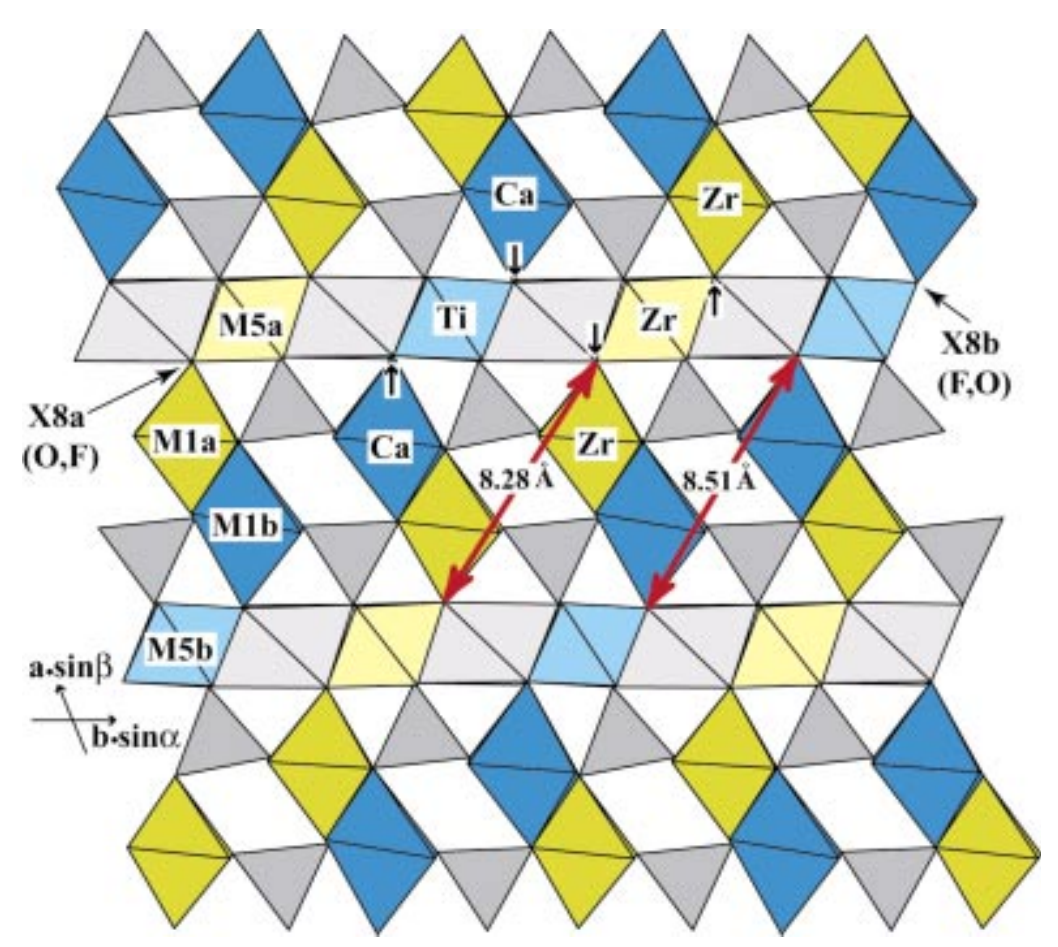

FIG. 12. Part of the structure of rosenbuschite seen along the $c$ axis. The figure shows the relationship between the degree of order of the cations in the $M 1$ and M5 octahedra. Black arrows indicate the direction of movement of the ligands from their "ideal" position. The dimensions are given in $\AA$. 
nounced rotation. The small rotation of the Si1 tetrahedron correlates in this way with a relatively shorter edgelength $(O 6-X 8)$ of the $M 2$ a octahedron $(3.30 \AA)$, and the larger rotation of the $\mathrm{Si} 2$ tetrahedron correlates with a longer edge-length $(O 7-X 8)$ of the $M 2 \mathrm{~b}$ octahedron $(3.56 \AA)$. However, the configuration with the Si2 tetrahedra more rotated than the Sil tetrahedra is valid for the whole group. The degree of rotation thus cannot only be due to the sizes of the $M 2$ octahedra.

The two tetrahedra also differ in the attachment to the immediately adjacent $H$-layer. The $S i 1$ tetrahedron is linked to the M3 octahedron (not shown in Fig. 13), and the $\mathrm{Si} 2$ tetrahedron is linked to the $M 1$ octahedron. In Figure 13, the apex by which the $S i 2$ tetrahedron is linked to the adjacent $H$-layer is indicated by a black circle (O3). A white arrow indicates that this point is pulled toward the relatively small $M 1$ octahedra, causing a larger degree of rotation of the $\mathrm{Si} 2$ tetrahedron. The Si1 tetrahedron is attached to the relatively larger M3 octahedron (not shown in the figure), and thus has a smaller degree of rotation.
In seidozerite, the smaller size of the $M 2 \mathrm{a}$ octahedron is therefore best accommodated by being linked to two Sil tetrahedra. The situation on both sides of an $\mathrm{HOH}$ layer thus will be equivalent, resulting in the displacement of two adjacent $\mathrm{HOH}$-layers in the same direction (both $+\tau_{\mathrm{b}}$ or $-\tau_{\mathrm{b}}$ ) relative to the $\mathrm{HOH}$ layer sandwiched between them. This arrangement produces the monoclinic mode of stacking.

\section{The triclinic structures}

The triclinic structures are characterized by having uniform sizes of all $M 2$ octahedra. The overall effects of the rotations of the tetrahedra are therefore not correlated with any difference in size of the $M 2$ octahedra, as was observed in seidozerite. The respective enlargements and reductions resulting from the rotation of the tetrahedra are compensated by linking one Sil tetrahedron with a relatively small rotation and one $\mathrm{Si} 2$ tetrahedron with a larger rotation to each $M 2$ octahedron. Consequently, the displacements of the two adjacent
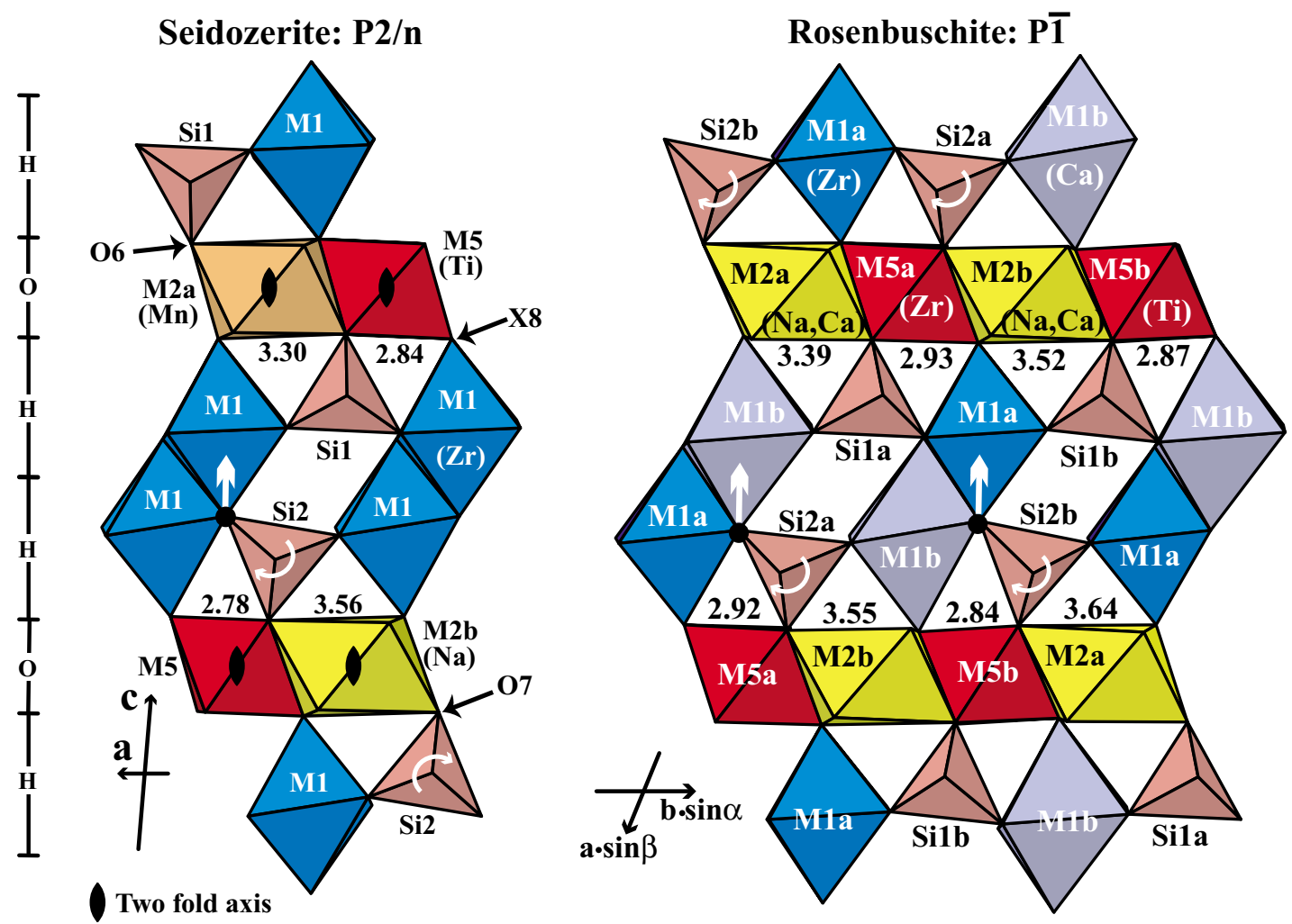

FIG. 13. Part of the structures of seidozerite and rosenbuschite showing the relationship among the sizes of the $M 2$ octahedra, rotations of the Si tetrahedra and the attachment of tetrahedra to the adjacent $H$ layer. The $O 3$ positions are indicated by a black circle. The $H$ and $O$ layers are indicated to the left. The distances between $X 8$ and the tetrahedron vertices common to the $O$ layer are given in $\AA$. 
$\mathrm{HOH}$-layers are in opposite directions relative to the central $\mathrm{HOH}$-layer, resulting in the triclinic mode of stacking.

In the triclinic structures, the difference in the rotations of the tetrahedra is not as distinct as in seidozerite. In the variants of the rosenbuschite structure, the $\mathrm{Zr}-\mathrm{Ca}$ order at the $M 1$ sites also has a significant effect upon these rotations (Fig. 13). The Sila tetrahedron has a low degree of rotation $\left(2.97^{\circ}\right)$, the $S i 2$ a and $S i 1$ b tetrahedra are rotated $6.21-6.43^{\circ}$, and the $S i 2 \mathrm{~b}$ tetrahedron has a high degree of rotation $\left(11.27^{\circ}\right)$. With respect of the $S i 1$ a and Si2a tetrahedra, their edges facing the M5 octahedron are also connected to the relatively small $M 1 \mathrm{a}$ octahedron, whereas the corresponding edges of Silb and $S i 2 \mathrm{~b}$ are connected to the larger $M 1 \mathrm{~b}$ octahedron. The combination of one small M5 and one large $M 1 \mathrm{~b}$ octahedron joined to the same tetrahedron-edge favors a higher degree of rotation of the tetrahedron, when compared to the case with the small M1a octahedron joined to the same tetrahedron-edge as the M5 octahedron. Furthermore, the $O 3 \mathrm{~b}$ corner of the Si2b tetrahedron is pulled toward the small M1a octahedron of the immediately adjacent $H$-layer, resulting in the largest rotation of the tetrahedra.

\section{Conclusions:}

1) Götzenite, hainite, kochite, rosenbuschite and seidozerite are based on the same fundamental structure, and they are considered members of the rosenbuschite group.

2) All members are triclinic, with space group $P \overline{1}$, except for seidozerite, which has monoclinic symmetry $P 2 / n$. Seidozerite is a configurational polytype to the other members of the group.

3) In this work, five different members of the group have been established. The general formula for the group can be represented by $(M 1)_{4}(M 2)_{4}(M 3)_{4}(M 4)_{2}$ $(M 5)_{2}\left(\mathrm{Si}_{2} \mathrm{O}_{7}\right)_{4} \mathrm{~F}_{4} X_{4}$. Götzenite and hainite have unit cells half the size of those of rosenbuschite and seidozerite, and their general formulae are accordingly halved. Simplified formulas for each member, following the scheme, are:

$$
\begin{aligned}
& \text { Götzenite: } \mathrm{Ca}_{2}(\mathrm{Ca}, \mathrm{Na})_{2} \mathrm{Ca}_{2} \mathrm{NaTi}\left(\mathrm{Si}_{2} \mathrm{O}_{7}\right)_{2} \mathrm{~F}_{2} \mathrm{~F}_{2} \\
& \text { Hainite: }(\mathrm{Ca}, \mathrm{Zr}, \mathrm{Y})_{2}(\mathrm{Na}, \mathrm{Ca})_{2} \mathrm{Ca}_{2} \mathrm{NaTi}\left(\mathrm{Si}_{2} \mathrm{O}_{7}\right)_{2} \mathrm{~F}_{2} \mathrm{~F}_{2} \\
& \text { Kochite: } \\
& \mathrm{Zr}_{2}(\mathrm{Mn}, \mathrm{Zr})_{2}(\mathrm{Na}, \mathrm{Ca})_{4} \mathrm{Ca}_{4} \mathrm{Na}_{2} \mathrm{Ti}_{2}\left(\mathrm{Si}_{2} \mathrm{O}_{7}\right)_{4} \mathrm{~F}_{4} \mathrm{O}_{4} \\
& \text { Rosenbuschite: } \\
& \mathrm{Zr}_{2} \mathrm{Ca}_{2}(\mathrm{Na}, \mathrm{Ca})_{4} \mathrm{Ca}_{4} \mathrm{Na}_{2} \mathrm{ZrTi}\left(\mathrm{Si}_{2} \mathrm{O}_{7}\right)_{4} \mathrm{~F}_{4} \mathrm{O}_{4}
\end{aligned}
$$$$
\text { Seidozerite: } \mathrm{Zr}_{4} \mathrm{Na}_{2} \mathrm{Mn}_{2} \mathrm{Na}_{4} \mathrm{Na}_{2} \mathrm{Ti}_{2}\left(\mathrm{Si}_{2} \mathrm{O}_{7}\right)_{4} \mathrm{~F}_{4} \mathrm{O}_{4}
$$

4) The $M 1$ site hosts a variety of cations of different crystal-chemical properties: $\mathrm{Ca}, \mathrm{Zr}, \mathrm{Mn}$ and $\mathrm{Y}$. The octahedron assumes different dimensions in order to accommodate these cations. This flexibility has a significant effect upon the size and deformation of the adjacent polyhedra and $\mathrm{Si}_{2} \mathrm{O}_{7}$ groups: a) The size of the M5 octahedron does not vary much, but the M5a octahedron connected to the Zr-dominated M1a octahedra differs from $M 5 \mathrm{~b}$ in that it may contain significant amount of $\mathrm{Zr}$. The M5a octahedron is slightly larger than $M 5 \mathrm{~b}$ and has a higher O:F ratio in the $X 8$ sites. b) The $\mathrm{Si}_{2} \mathrm{O}_{7}$ groups show three modes of bending, depending on the size of the two $M 1$ octahedra. c) The degree of bending relates directly to a stretching of the $M 3$ and M4 polyhedra, and also to the interatomic distance between these cations and $O 1$. In the rosenbuschite variant of the structure, the $M 3$ site, with the shortest distance to $O 1$, contains significant amount of $\mathrm{Na}(25 \%)$. $M 4$ is invariably within bonding distance to $O 1$ and dominated by Na.

5) The column of $M 2$ octahedra hosts $\mathrm{Na}$ and $\mathrm{Ca}$ only in the triclinic structure-type. In the monoclinic seidozerite, a smaller Mn octahedron is incorporated into this column, resulting in its shorter periodicity.

6) Our data indicate that $\mathrm{Ca}$ and $\mathrm{Zr}$ in the $M 1$ position are only partially replacable. Chemical data suggest a solid-solution series between götzenite and rosenbuschite, and a compositional gap between rosenbuschite and seidozerite. Such a gap between rosenbuschite and seidozerite is explained by a dimensional misfit between the two structures, which cannot be compensated. This misfit results from differently sized octahedra and different mode of stacking of $\mathrm{HOH}$ layers. The $\mathrm{Ca} \leftrightarrow \mathrm{Zr}$ replacement in the götzeniterosenbuschite compositional series is compensated by adjusting the shape of the surrounding octahedra.

7) Zirconium may both replace $\mathrm{Ca}$ in the $\mathrm{M} 1 \mathrm{a}$ site and substitute for Ti in M5a. This results in two compositional series. One series occurs between götzenite and kochite, in which $\mathrm{Zr}$ replaces $\mathrm{Ca}$, and another between kochite and rosenbuschite, in which $\mathrm{Zr}$ substitutes for Ti. The $\mathrm{Zr} \leftrightarrow$ Ti substitution is only observed in the $M 5 \mathrm{a}$ position in those specimens in which $\mathrm{Zr}$ dominates at the $M 1$ a site.

8) The two modes of stacking of $\mathrm{HOH}$ layers in the configurational polytypes are related to the sizes of the $M 2$ octahedra and the occupancy of the $M 1$ positions. The monoclinic polytype is favored by two differently sized $M 2$ octahedra and domination of $\mathrm{Zr}$ in the $M 1$ sites, whereas the triclinic polytype is correlated with equally sized $M 2$ octahedra and full or partial occupancy of $\mathrm{Ca}$ at the $M 1$ sites.

\section{ACKNOWLEDGEMENTS}

We are indebted to: R.A. Gault, Canadian Museum of Nature, for his electron-microprobe analyses of the 
specimens investigated, T. Balić-Žunić, University of Copenhagen, for his assistance during collection of single-crystal-diffractometry data, J.D. Grice, Canadian Museum of Nature, for fruitful discussions during the work, Alf Olav Larsen, who generously provided numerous specimens of the rosenbuschite group of minerals from the Langesund Fjord area, Norway, and to Dan Holtstam, the Museum of Natural History in Stockholm, who kindly provided the type material of rosenbuschite. We also thank the referees G. Ferraris and E. Sokolova for their helpful comments about the manuscript. The work was supported by the Danish Natural Science Research Council.

\section{REFERENCES}

Atencio, D., Coutinho, J.M.V., Ulbrich, M.N.C., Vlach, S.R.F.., Rastsvetaeva, R.K. \& Pushcharovsky, D.Yu. (1999): Hainite from Poços de Caldas, Minas Gerais, Brazil. Can. Mineral. 37, 91-98.

Balić-Žunić, T. \& Vickovic, K. (1996): IVTON, a program for the calculation of geometrical aspects of crystal structures and some crystal chemical applications. J. Appl. Crystallogr. 29, 305-306.

Betti, F. (1998): Cristallochimica di silicati con formula generale $\mathrm{X}_{16}\left(\mathrm{Si}_{2} \mathrm{O}_{7}\right)_{4}(\mathrm{O}, \mathrm{OH}, \mathrm{F})_{8}$. Master's thesis, Università degli Studi di Pisa, Pisa, Italy.

Blumrich, J. (1893): Die Phonolithe des Friedländer Bexirkes in Nordböhmen. Tschermaks Mineral. Petrogr. Mitt. 13, 465-495.

Brese, N.E. \& O'KeEFFe, M. (1991): Bond-valence parameters for solids. Acta Crystallogr. B47, 192-197.

BRÖGGER, W.C. (1887): Forelöbig meddelelse om mineralerne på de sydnorske augit- og nefelinsyeniters grovkornige gange. Geol. Fören. Stockholm Förh. 109, 247-274.

(1889): Vorläufige Mittheilung über die Mineralien der grobkörnigen gänge der Südnorwegischen Augit- und Nephelinsyenite. Z. Kristallogr. Mineral. 15, 103-104.

(1890): Die Mineralen der Syenitpegmatitgänge der Südnorwegischen Augit- und Nephelinsyenite. Z. Kristallogr. Mineral. 16.

BulakH, A.G. \& Kapustin, Yu.L. (1973): Götzenite from the alkaline rocks of the Tur'yev Peninsula, Kola Peninsula. Zap. Vses. Mineral. Obschhest. 102(4), 464-466.

Cannillo, E., Mazzi, F. \& Rossi, G. (1972): Crystal structure of götzenite. Sov. Phys. Crystallogr. 16, 1026-1030.

Christiansen, C.C., Gault, R.A., Grice, J.D. \& Johnsen, O. (2003): Kochite, a new member of the rosenbuschite group from the Werner Bjerge alkaline complex, East Greenland. Eur. J. Mineral. 15, 551-554.
Makovicky, E. \& JoHnSEN, O. (1999): Homology and typism in heterophyllosilicates: an alternative approach. Neues Jahrb. Mineral., Abh. 175, 153-189.

\& RønsBo, J.G. (2000): On the structural relationship between götzenite and rinkite. Neues Jahrb. Mineral., Monatsh., 496-506.

Cundari, A. \& Ferguson, A.J. (1994): Appraisal of the new occurrence of götzenite $_{\text {ss }}$, khibinskite and apophyllite in kalsilite-bearing lavas from San Venanzo and Cupaello (Umbria), Italy. Lithos 31, 155-161.

Egorov-Tismenko, Yu.K. \& Sokolova, E.V. (1990): Structural mineralogy of the homologous series seidozeritenacaphite. Mineral. Zh. 12(4), 40-49 (in Russ.).

FERraris, G. (1997): Polysomatism as a tool for correlating properties and structure. In Modular Aspects of Minerals (S. Merlino, ed.). Eur. Mineral. Union, Notes in Mineralogy 1, 275-295.

, Ivaldi, G., Khomyakov, A. P., Soboleva, S. V., Belluso, E. \& Pavese, A. (1996): Nafertisite, a layer titanosilicate member of a polysomatic series including mica. Eur. J. Mineral. 8, 241-249.

JoHAN, Z. \& Č ECH, Z. (1989): New data on hainite, $\mathrm{Na}_{2} \mathrm{Ca}_{4}$ [(Ti, $\left.\mathrm{Zr}, \mathrm{Mn}, \mathrm{Fe}, \mathrm{Nb}, \mathrm{Ta})_{1.5} \square_{0.5}\right]\left(\mathrm{Si}_{2} \mathrm{O}_{7}\right)_{2} \mathrm{~F}_{4}$ and its crystal chemical relationship with götzenite, $\mathrm{Na}_{2} \mathrm{Ca}_{5} \mathrm{Ti}\left(\mathrm{Si}_{2} \mathrm{O}_{7}\right)_{2} \mathrm{~F}_{4}$. C.R. Acad. Sci. Paris 308(II), 1237-1242.

MaKovicky, E. (1997): Modularity - different types and approaches. In Modular Aspects of Minerals (S. Merlino, ed.). Eur. Mineral. Union, Notes in Mineralogy 1, 315-343.

\& BALIĆ-Žunić, T. (1998): New measure for distortion for coordination polyhedra. Acta Crystallogr. B54, 766-773.

Mellini, M. (1981): Refinement of the crystal structure of låvenite. Tschermaks Mineral. Petrogr. Mitt. 28, 99-112.

Men'shikov, Yu.P., Pakhomovsky, Ya.A \& Yakovenchuk, V.N. (1999): Rosenbuschite from the Khibiny alkaline massif. Zap. Vser. Mineral. Obshchest. 128(1), 63-68.

Neumann, H. (1962): Rosenbuschite and its relation to götzenite. Norsk Geol. Tidsskr. 42, 179-186.

PeAcock, M.A. (1937): On rosenbuschite. Norsk Geol. Tidsskr. 17, 17-30.

Perchiazzi, N., McDonald, A.M., Gault, R.A., Johnsen, O. \& MerLino, S. (2000): The crystal structure of normandite and its crystal-chemical relationships with låvenite. Can. Mineral. 38, 641-648.

Pushcharovskit, D.Yu., Pasero, M., Merlino, S., Vladykin, N.D., Zubkova, N.V. \& GobechiYA, E.R. (2002): Crystal structure of zirconium-rich seidozerite. Crystallogr. Rep. 47(2), 196-200. 
Rastsvetaeva, R.K., Pushcharovskit, D.Yu. \& Atencio, D. (1995): Crystal structure of giannetite. Crystallogr. Rep. 40, 574-578.

Sahama, T.G. \& Hytönen, M.A. (1957): Götzenite and combeite, two new silicates from the Belgian Congo. Mineral. Mag. 238, 503-510.

SAARI, E. \& Hytönen, M.A. (1966): Relationship between götzenite and rosenbuschite. Bull. Comm. Géol. Finlande 222, 135-144.

Semenov, E.I., Kazakova, M.E. \& Simonov, V.I. (1958): A new zirconium mineral, seidozerite, and other minerals of the wöhlerite group in alkaline pegmatites. Zap. Vses. Mineral. Obschest. 87, 590-597 (in Russ.).

SHANNON, R.D. (1976): Revised effective ionic radii and systematic studies of interatomic distances in halides and chalcogenides. Acta Crystallogr. A32, 751-767.

Sharygin, V.V., Stoppa, F. \& Kolesov, B.A. (1996): Zr-Ti disilicates from the Pian di Celle volcano, Umbria, Italy. Eur. J. Mineral. 8, 1199-1212.
Shibaeva, R.P., Simonov, V.I. \& Belov, N.V. (1964): Crystal structure of the $\mathrm{Ca}, \mathrm{Na}, \mathrm{Zr}$, Ti silicate rosenbuschite, $\mathrm{Ca}_{3.5} \mathrm{Na}_{2.5} \mathrm{Zr}(\mathrm{Ti}, \mathrm{Mn}, \mathrm{Nb})\left[\mathrm{Si}_{2} \mathrm{O}_{7}\right]_{2} \mathrm{~F}_{2} \mathrm{O}(\mathrm{F}, \mathrm{O})$. Sov. Phys. Crystallogr. 8, 406-413.

Simonov, V.I. \& Belov, N.V. (1960): The determination of the structure of seidozerite. Sov. Phys. Crystallogr. 4, 146157

SksZat, S.M. \& Simonov, V.I. (1966): The structure of calcium seidozerite. Sov. Phys. Crystallogr. 10, 505-508.

ZACHARIASEN, W.H. (1930): The chemical formula of the zircon pyroxenes and the zircon pectolite. Norsk Geol. Tidsskr. 11, 216-218.

Received August 4, 2002, revised manuscript accepted August 27, 2003. 